EFFEC'IS OF PHONF'TLC PROCEGSTNG AND STIMULUS RELEVANCE ON THE AUDITORY EVOKED RESPONSE

By

DENNIS ALFRED SILVA

A DISSERTATTON PRESENTED 'YO THE GRADUATE COUNCIL OF THE UNTVERSTIYY OF FLORIDA

IN PAR'TIAL FULFTLKMEN'T OF 'THF REQUIREMENTS FOR THE DEGREE OF DOCTOR OF PHILUSOPHY

UNIVERSITY OF FLORIDA

1977 
Copyright by

Dennis Alfred Silva

1977 
I wish to express my sincere appreciation to William Yost, chairman of my committee, not only for his helpful suggestions for the present investigation, but also for his tremendous contributions to my graduate education. In addition, I wish to thank Donald Teas for the use of his laboratory facilities which made the present research possible, as well as for his useful comments on the work itself. I would like to express my appreciation also to my other committee members, Keith Berg, Howard Rothman, Paul Satz, and Robert Isaacson, for their knowledgeable comments and suggestions. 
TABLE OF CONTENTS

Page

ACKNOWLEDGMENTS. . . . . . . . . . . . . . . . . . . .

ii i

LIST OF TABLES........................

LIST OF FIGURES $\ldots \ldots \ldots \ldots \ldots \ldots \ldots \ldots \ldots \ldots \ldots \ldots \ldots \ldots \ldots \ldots \ldots$ vi

ABSTRACT $\ldots \ldots \ldots \ldots \ldots \ldots \ldots \ldots \ldots \ldots \ldots \ldots \ldots \ldots \ldots \ldots \ldots \ldots \ldots \ldots \ldots$

INTRODUCTION . . . . . . . . . . . . . . . .

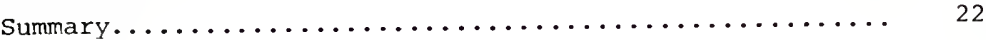

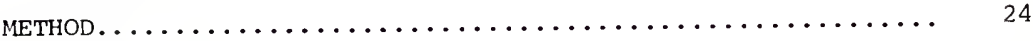

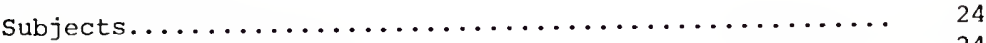

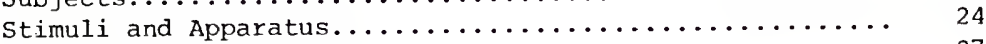

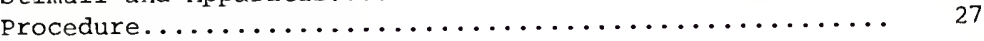

RESULTS.................................. 32

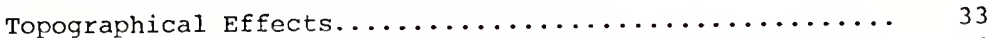

Phonetic versus Nonphonetic Tape Effects............. 44

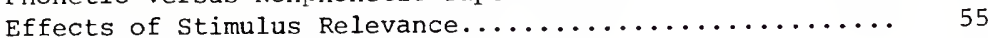

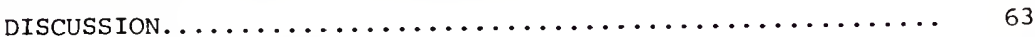

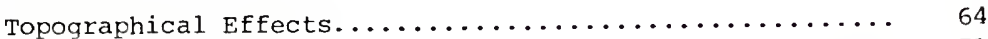

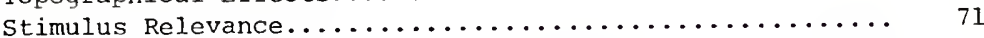

APPENDIX A: Ordering of Stimuli on Tape $1 \ldots \ldots \ldots \ldots \ldots \ldots .74$

APPENDIX A: Ordering of stimuli on Tape $2 \ldots \ldots \ldots \ldots \ldots \ldots 75$

APPENDIX B: Order of Experimental Conditions.......... 76

APPENDIX C: Summary of Partial Amplitude Data (Microvolts) 77

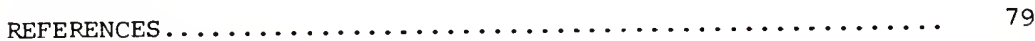

BIOGRAPHICAL SKETCH..................... 87 
1 Summary of Experimental Conditions..........

2 Mean Amplitudes (microvolts) for Major Components of Evoked Responses Recorded from Three Locations.

3 Number of Persons Having Greater Left Hemisphere Amplitudes for Various Components.......

4 Mean Latencies (msec) for Major Components of Evoked Responses Recorded from Three Locations..

5 Mean Amplitudes (microvolts) for Major Components of Potentials Evoked by Stimuli on

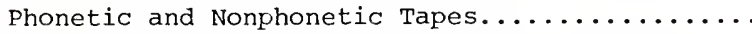

6 Mean Latencies (msec) for Major Components of Potentials Evoked by Stimuli on Phonetic and Nonphonetic Tapes.

Significant Wilcoxen Tests between Potentials Evoked by Stimuli on Phonetic and Nonphonetic

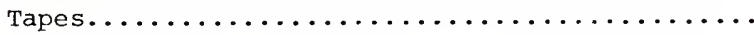


1 Averaged evoked potentials to $\mathrm{CV}$ stimulus recorded from vertex, left, and right temporo-parietal sites

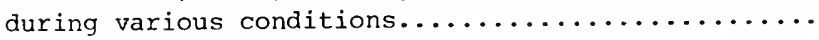

2 Averaged evoked potentials to $\mathrm{T}_{1}$ stimulus recorded from vertex, left, and right temporo-parietal sites

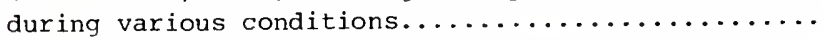

R-values and hemispheric voltage differences for

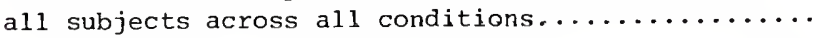

4 Latencies for $\mathrm{N}_{1}$ component of potentials evoked by $\mathrm{CV}_{1}$ during phonetic and nonphonetic processing

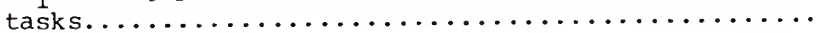

5 Averaged evoked potentials recorded from left and right hemispheres during phonetic and nonphonetic

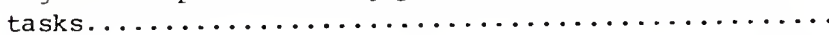

6 Averaged evoked potentials recorded from the vertex to $\mathrm{CV}_{1}$ and $\mathrm{T}_{1}$ evoking stimuli during conditions of

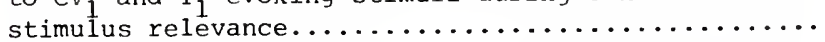

7 Averaged evoked potentials recorded from Subjects $1-4$ during conditions of stimulus relevance.......

8 Averaged evoked potentials recorded from Subjects $5-8$ during conditions of stimulus relevance....... 
Abstract of Dissertation Presented to the Graduate Council of the University of Florida in Partial Fulfillment of the Requirements for the Deqree of Doctor of Philosophy

\section{EFFECTS OF PHONETIC PROCESSING AND STIMULUS RELEVANCE ON THE AUDITORY EVOKED RESPONSE}

By

Dennis Alfred Silva

March 1977

Chairman: William A. Yost

Major Department: Psychology

There is a substantial body of research data, gathered from both clinical and nonclinical behavioral investigations, which support the phenomenon of specialization of function in the human brain. In addition, recent findings suggest that there are structural asymmetries in the cortex which parallel the functional differences. Results of recent electrophysiological investigations suggest that the left hemisphere's specialization for language is reflected in auditory evoked responses to speech and nonspeech stimuli and during phonetic and nonphonetic processing of speech stimuli. Because of several inconsistencies in the existing data, however, the precise nature of the effect as well as the actual processing mechanisms reflected in the reported asymmetries remain obscure. For example, the evoked potential asymmetries might be reflecting the activity of a lateralized neural center responsible for phonetic analysis of speech stimuli or they might be due to a lateralized cortical activation occurring in preparation for phonetic processing. 
One purpose of the present investigation was to investigate further the evoked potential correlates of hemispheric specialization for language by recording auditory evoked responses to a speech and a nonspeech stimulus from left and right temporoparietal locations (referred to linked mastoids).

Eight subjects participated in a series of phonetic and nonphonetic discrimination tasks. During each condition two speech (CV syllables) and two nonspeech (tones) stimuli were presented to subjects and evoked potentials were averaged to one of each class of stimuli. In one type of task the speech stimuli were phonetically different (/ba/ and $/ \mathrm{da} /$ ); in the other type they were phonetically similar $(/ \mathrm{ba} /)$ but differed in fundamental frequency. By presenting both speech and nonspeech stimuli within a single run while subjects are engaged in tasks reauiring either a "phonetic" or "nonphonetic" cognitive set, it is possible to determine if an evoked potential asymetry is due to a lateralized preparatory activation or to the activity of an actual phonetic analyzer localized in the left hemisphere. If the former explanation is correct, then asymmetrical cortical responses should be manifest in the evoked potential to a stimulus whenever a subject expects to make a phonetic discrimination, regardless of the actual nature of the stimulus presented. If the latter explanation is correct then an asymmetrical response should occur only to a speech stimulus and not to a nonspeech stimulus in spite of a "phonetic set." 
Analysis of the data demonstrated no significant differences between the left and right hemispheres for mean amplitudes or mean latencies of the evoked potential components. The majority of subjects, however, did have slightly larger left hemisphere responses to both evoking stimuli.

Regarding potentials obtained during phonetic and nonphonetic processing of stimuli, the data confirm a previously reported finding of a differential left hemisphere response to a speech stimulus during phonetic processing and extend this observation to the use of natural speech syllables. No differences in potentials occurred to the nonspeech stimulus even when subjects were engaged in the phonetic processing task. This suggests that the differential left hemisphere response is not simply one of a preparatory nature but rather it may reflect the activity of a phonemic analyzer. The possibility of two left hemisphere mechanisms was discussed -- one for speech detection and one for phonetic analysis.

Finally, vertex potentials were analyzed for effects of stimulus relevance, with the stimulus which subjects were discriminating being the relevant stimulus and the other three stimuli being irrelevant stimuli. It was found that the $\mathrm{P}_{3}$ component of the evoked potential was most sensitive to various conditions of stimulus relevance. The amplitude of the $\mathrm{P}_{3}$ component was largest when the evoking stimulus was most like the relevant stimulus, and smallest when the evoking stimulus was of the other class (i.e. speech or nonspeech) than the relevant stimulus. These findings support a "neural template" model of $\mathrm{P}_{3}$. 


\section{INTRODUCTION}

Since the nineteenth century when anatomists and neurologists first noted a relationship between sensory-motor disorders of the right half of the body and speech disturbances, mounting scientific evidence attests to the functional disparity in humans between the two cerebral hemispheres with respect to certain cognitive capacities. Over the years the understanding of cerebral specialization in the human brain has grown, and investigation of the phenomenon has expanded from predominantly clinical observations to research with non-brain damaged persons in a variety of experimental paradigms. Novel approaches and more sophisticated apparatus have resulted in an expansion of methodologies for investigating functional localization in the brain. Not only have behavioral experiments flourished, but, during the last eight years or so, reports of electrophysiological investigations of the phenomenon have begun to appear in the literature. The purpose of the present report is to expand further our knowledge of evoked potential correlates of language localization in the brain while attempting to integrate some of the existing data on hemispheric asymetries. The effects of phonetic processing and stimulus relevance on the auditory evoked response to speech and nonspeech stimuli are addressed in the present investigation. 
With respect to their localization in the brain, speech and language functions are perhaps the most extensively studied and documented of human cognitive processes. A substantial amount of the clinical evidence for the localization of language in the left hemisphere comes from the work of Penfield and Roberts (1959). Those authors reported that, excluding persons with cerebral injury occurring prior to age two, over 70 percent of their patients who had surgery on the left hemisphere showed transient dysphasia. This was so for both right and left handers. In contrast, they found that fewer than 1 percent of right and fewer than 7 percent of left handers showed dysphasic symptoms following operation on the right hemisphere.

Penfield and Roberts (1959) showed also that electrical stimulation of certain areas of the left hemisphere can cause an arrest or a hesitation of speech or can result in a variety of dysphasic responses such as misnaming, word distortion or repetition, and perseveration. They reported that stimulation of three regions of the brain in particular could alter speech processes: (1) Broca's area (the three gyri anterior to the lower precentral gyrus); (2) the supplementary motor area (on the medial surface of the brain anterior to the precentral leg area); and (3) the posterior temporo-parietal area (the posterior part of the first, second, and third temporal convolutions; the supramarginal gyrus; and the angular gyrus).

Lateralized cortical lesions have been shown to result in significant deficits in performance on verbal intelligence tests 
when these lesions occur on the left side but not on the right (Heilbrun, 1956; Klove, 1959; McFie \& Piercy, 1952; Reitan, 1955; Satz, Richard, \& Daniels, 1967), although Milner (1958) noted that if the disorder is restricted to the left temporal lobe this deficit does not occur. She did report, however, as had others previously, that learning capacities and memory for verbal material is impaired following left temporal lobe lesion (Meyer \& Yates, 1955; Milner, 1958).

Additional clinical evidence for lateralization of language functions in the left hemisphere comes from persons having undergone the Wada sodium amytal test (Branch, Milner, \& Rasmussen, 1964; Wada \& Rasmussen, 1960) or the surgical sectioning of the forebrain commissures.

The wada test was developed as an alternative to using manifest handedness as the sole means for identifying cerebral dominance in patients about to have surgery. The technique consists of injecting a barbiturate, sodium amytal, into the right and left carotid arteries on separate occasions, thereby influencing the functioning of the right and left hemispheres individually. The wada treatment results in a temporary interference with normal hemisphere functions and thus allows for comparison of the roles of each side of the brain in speech and language. Treatment on the side of the language dominant hemisphere, therefore, typically results in a transient interference of expressive and receptive language functions (Branch et al., 
1964; Perria, Rosadini, \& Rossi, 1961; Terzian, 1964; Wada \& Rasmussen, 1960). In contrast, injection of the barbiturate on the nondominant side has been reported to impair musical ability (Bogen \& Gordon, 1971; Gordon \& Bogen, 1974).

Sectioning of the forebrain commissures for the control of epileptic seizures has provided a yet different means to evaluate the capabilities of each hemisphere, independent of the influence of the other. In the human, commissural sectioning has been successful clinically, but as a research resource human studies have been somewhat inconclusive. In most of these cases the left hemisphere is clearly the dominant one for language functions although there is some evidence that the right hemisphere does possess at least minimal receptive and expressive capabilities (Gazzaniga \& Hillyard, 1971; Gazzaniga \& Sperry, 1967; Levy, Nebes, \& Sperry, 1971). Because of factors such as preexisting brain damage and cross-cueing strategies between the two hemispheres, however, more sophisticated capabilities of the nondominant right hemisphere remain unresolved.

Over the years, investigators have searched for structural and physiological differences between the hemispheres that might account for observed differences in function. Recently, several studies have reported left-right asymmetries in humans in the region posterior to Heschl's gyrus on the superior aspect of the temporal lobe (Geschwind \& Levitsky, 1968; Wada, Clarke, \& Hamm, 1975; Witelson \& Pallie, 1973). This area, the planum temporale, comprises 
part of the region classically known as Wernicke's area and has been shown to be of major importance in language function (Penfield \& Roberts, 1959). This left-right anatomical difference has been reported to be present as early as the 29 th gestational week (Wada et al., 1975). Other asymmetries have been reported to exist in humans: the length of the sylvian fissure, with the left being approximately $10 \mathrm{~mm}$ longer than the right (Yeni-Komshian \& Benson, 1976); and the pathway of the middle cerebral artery in the region of the Sylvian fissure which suggests a larger parietal operculum on the left (LeMay \& Culebras, 1972).

In addition to the research with clinical populations described earlier, a vast number of behavioral investigations have been conducted with nonclinical subjects. Experimental paradigms in both the visual and auditory modalities have provided a means for investigating laterality of function in the cerebral hemispheres.

In man approximately half of the fibers originating from each eye are contralateral. Fibers from the nasal half of the retina cross at the optic chiasm and higher order neurons eventually terminate in the opposite striate cortex. Fibers from the temporal halves remain uncrossed and their higher order neurons eventually terminate in the ipsilateral receiving area. Consequently, perception of visual stimuli in the left visual half-field (impinging on the right hemi-retinae) occurs in the right occipital lobe, and perception of visual stimuli in the right visual half-field (impinging on the left hemi-retinae) occurs in the left hemisphere. 
Experimenters have found that when a stimulus is presented to an observer so that it is confined to a single visual half-field (i.e. the left or right), the field of presentation which results in the superior recognition is dependent on the nature of the stimulus. For example, a right half-field superiority is obtained most frequently with words (Kaufer, Morais, \& Bertelson, 1975; McKeever \& Huling, 1971; Mishkin \& Forgays, 1952; Terrace, 1959), letters (Bryden, 1965, 1966; Bryden \& Rainey, 1963; Heron, 1957; Kimura, 1966), and digits (Hines \& Satz, 1971; White, 1969), whereas no signficant field differences are usually found when stimuli consist of nonalphabetic material such as geometric shapes or nonsense forms (Bryden, 1960; Bryden \& Rainey, 1963; Heron, 1957; Kimura, 1966; Terrace, 1959). Recognition of faces is superior when they are presented to the left visual half-field (Ellis \& Shepherd, 1975) .

Because words and letters, but not geometric or nonsense forms, are identified more accurately in the right visual field, Kimura (1966) suggested that the more direct pathway from that field to the language dominant left hemisphere is the basis for the visual field differences. Reaction time data employing the visual half-field paradigm also support a cerebral dominance model: observers respond faster to verbally coded stimuli when they are presented in the right visual half-field (Cohen, 1972; Geffen, Bradshaw, \& Nettleson, 1972; Geffen, Bradshaw, \& Wallace, 1971; Seamon \& Gazzaniga, 1973), while 
the use of nonverbal stimuli results in faster reaction lines when they are presented in the left visual half-field (Rizzolatti, Umilta, \& Berlucci, 1971).

In the auditory modality a dichotic listening paradigm has been employed to study hemispheric differences in the processing of stimuli. This technique, introduced by Broadbent (1954), consists of presenting conflicting stimuli simultaneously to the two ears. The listener's task is to report the stimuli which he perceives.

Using the dichotic technique, Kimura (1961) found that both normal and temporal lobe brain damaged persons usually had higher scores for reporting verbal material presented to the right ear than to the left ear, with the exceptions being persons who had speech functions localized in the right hemisphere as determined by the wada test. Since the left hemisphere is the language dominant hemisphere in the vast majority of persons (Penfield \& Roberts, 1959), the ear asymmetry which occurs with dichotic stimulation is usually referred to as a right ear advantage. Since Kimura's early studies, the right ear advantage has been replicated with a variety of verbal stimuli including meaningful and nonsense words (Curry, 1967; Curry \& Rutherford, 1967); digits (Broadbent \& Gregory, 1964; Dirks, 1964); and backwards speech (Kimura \& Folb, 1968). Shankweiler and Studdert-Kennedy (1967) have shown that a right ear advantage is obtained with consonants but not with vowels. 
To explain her findings, Kumura suggested that the crossed auditory pathway in man is more efficient than the uncrossed pathway, thus providing the ear contralateral to the language hemisphere with a superior channel to the speech processor. Unlike the visual pathways, the fibers in the auditory system are bilateral. By proposing a greater efficiency for the contralateral pathway and a suppression of ipsilateral fibers during dichotic stimulation, however, Kimura (1967) was able to interpret the right ear advantage in audition in the same vein as the perceptual asymmetries in visual half-field investigations, i.e. superior transmission to the language dominant left hemisphere. Support for her model is derived from electrophysiological recordings in lower mammals which suggest that the contralateral auditory pathways are superior to the ipsilateral pathways (Benson \& Teas, 1976; Hall \& Goldstein, 1968; Rosenzweig, 1951; Tunturi, 1946).

Kinsbourne (1970) has proposed a model which attempts to account for laterality differences in perceptual experiments on the basis of an attentional bias toward stimuli coming from either the left or the right rather than on a perceptual asymetry resulting from differences in the neural pathways from sensory receptors to the language processing hemisphere. He suggested that the use of verbal stimuli "induces preparatory left hemisphere activation, and thus biases attention" (Kinsbourne, 1970, p. 196) to stimuli on the contralateral right side. Because of this selective attention to the right side, verbal stimuli 
to the right ear are more accurately recognized than verbal stimuli to the left ear. Likewise, since the right hemisphere is specialized to process nonverbal stimuli, their use activates the right hemisphere which in turn facilitates perception of stimuli presented to the contralateral left side. To support his model Kinsbourne presented data which showed that subvocal rehearsal of verbal stimuli (a process which should activate the language dominant left hemisphere) results in an increased perception of stimuli on the right side but not on the left.

At present it remains to be determined whether kimura's perceptual asymetry model or Kinsbourne's attention model is the better one, since both can account for the majority of the existing data. Both, however, rely on the left hemisphere's specialization for speech and language and thus support a cerebral dominance model for explaining performance asymetries in visual and auditory experiments.

In the early 1970's researchers began to investigate the possibility that lateralization of function in the cerebral hemispheres is reflected in cortical potentials recorded from the human scalp. Some researchers looked at ongoing electroencephalograms (EEG's) and found relatively less alpha activity on the left side when subjects were engaged in linguistic tasks (Galin \& Ellis, 1975; Galin \& Ornstein, 1972; McKee, Humphrey, \& McAdam, 1973; Morgan, MacDonald, \& Hilgard, 1974; Robbins \& McAdam, 1974; Wilson, Vieth, 
\& Darrow, 1957). In contrast, if a task is spatial in nature, a greater decrease in alpha is seen over the right hemisphere (Galin \& Ellis, 1975; Galin \& Ornstein, 1972; Morgan et al., 1974; Morgan, McDonald, \& MacDonald, 1971; Robbins \& MCAdam, 1974).

A second electrophysiological approach to studying hemispheric processing of information has been to compare sensory evoked cortical potentials recorded from the left and right hemispheres to linguistic and nonlinguistic stimuli. The sensory evoked response reflects electrical activity of the brain which is time-locked to a change in sensory input. When recorded from the human scalp the evoked response is typically represented as an average of many responses so as to minimize the random background activity of the EEG. In the auditory modality, the evoked response waveform has been subdivided into early components which occur within $8 \mathrm{msec}$, middle latency components occurring between 8 and $40 \mathrm{msec}$, and late components with latencies greater than $40 \mathrm{msec}$ (Picton, Hillyard, Krausz, \& Galambos, 1974). It is the late components, reflecting cortical activity, which have been investigated with respect to hemispheric differences.

When recorded from the vertex the late potentials include a series of alternating positive and negative waves traditionally labelled as $\mathrm{P}_{1}, \mathrm{~N}_{1}$, and $\mathrm{P}_{2}$, with latencies of approximately 50 , 100, and $180 \mathrm{msec}$, respectively (Davis, Mast, Yoshie, \& Zerlin, 1966; Davis \& Zerlin, 1966; Rothman, Davis, \& Hay, 1970). 
Depending on the experimental conditions, a third positive component may occur, typically at $300 \mathrm{msec}$ or longer following stimulus onset (Sutton, Braren, Zubin, \& John, 1965; Sutton, Tueting, Zubin, \& John, 1967). This late positive wave is usually referred to as $\mathrm{P}_{3}$ or, because of latency, $\mathrm{P}_{300}$. The negative peak between $\mathrm{P}_{2}$ and $P_{3}$ is called $N_{2}$ and usually appears between 250 and $300 \mathrm{msec}$ poststimulus onset.

Although the $\mathrm{N}_{1}$ and $\mathrm{P}_{2}$ components can be affected by changes in the stimulus parameters of intensity and duration (Butler, Keidel, \& Spreng, 1969; Davis et al., 1966; Onishi \& Davis, 1968; Rapin, Schimmel, Tourk, Krasnegor, \& Pollack, 1966), they are also sensitive to certain psychological variables. For example, the $\mathrm{N}_{1}-\mathrm{P}_{2}$ peakto-peak amplitude is increased when attention is enhanced through counting (Gross, Begleiter, Tobin, \& Kissin, 1965; Mast \& Watson, 1968) and in discrimination/detection tasks (Davis, 1964; Hirsch, 1971). When subjects are told to listen selectively to stimuli arriving through a particular channel (e.g., sense modality), the $\mathrm{N}_{1}-\mathrm{P}_{2}$ amplitude is larger than the corresponding amplitude evoked by the same stimuli arriving through a nonattended channel (Debecker \& Desmedt, 1966; Satterfield, 1965; Spong, Haider, \& Lindsley, 1965). Naatanen (1975) has chosen to explain this effect as being due to an increase in a subject's general arousal as opposed to his selective attention, but recent data presented by Schwent and Hillyard (1975) conflict with Naatanen interpretation. 
By presenting stimuli rapidly through different auditory "channels" (i.e., lateralized to the left or right) they were able to keep the subjects' arousal levels from fluctuating from stimulus presentation to stimulus presentation.

The $\mathrm{P}_{3}$ component of the evoked potential was shown by Sutton and colleagues to be dependent on psychological variables (Sutton et al., 1965, 1967). Since then, several investigations have been conducted in an effort to deliniate precisely what these variables are. It has been shown that the $\mathrm{P}_{3}$ wave can be evoked by stimuli which deliver information relevant to the task of a subject (Donchin \& Cohen, 1967; Sutton et al., 1965, 1967), by stimuli about which a decision must be made (Rohrbaugh, Donchin, \& Eriksen, 1974; Smith, Donchin, Cohen, \& Starr, 1970), and by novel or unexpected stimuli (Ritter \& Vaughan, 1969; Ritter, Vaughan, \& Costa, 1968).

In 1971 reports began to appear in the literature describing hemispheric differences in auditory evoked responses to speech and nonspeech stimuli. Unfortunately, it is not possible to integrate all the data presently available because neither methodologies nor dependent measures have been consistent among different investigators.

Morrell and Salamy (1971) measured responses from frontal leads (over Broca's area), from Rolandic leads (over the sensory-motor field of vocalization muscles), and from temporo-parietal leads 
(over Wernicke's area) to verbal nonsense words. They compared the peak amplitudes of the $\mathrm{N}_{1}$ and $\mathrm{P}_{2}$ components and the peak-topeak $\mathrm{N}_{1}-\mathrm{P}_{2}$ amplitude. They found that the $\mathrm{N}_{1}$ wave was significantly larger from the left hemisphere than from the right hemisphere, particularly in the temporoparietal region. No hemisphere difference was found when the amplitudes of the $\mathrm{P}_{2}$ waves were compared. In addition, those authors reported that the peak-topeak measurements tended to obscure the hemisphere differences that did occur. Since nonverbal stimuli were not employed in that study it is not known whether the hemispheric asymmetries obtained by Morrell and Salamy were specific to the use of speech or speech-like signals or if they might have occurred also with other stimuli.

Cohn (1971) compared the left and right hemisphere responses to monosyllabic speech stimuli and to click stimuli. He reported that in about half of his subjects the verbal stimuli produced an initial negative wave, largest in the temporo-parietal region, which peaked between 30 and $50 \mathrm{msec}$. The remaining subjects showed no hemisphere differences with these stimuli. The significance of Cohn's findings is questionable, however, because the stimuli he employed were not equated on the basis of duration, rise-decay time, frequency composition, and other physical parameters.

Molfese, Freeman, and Palermo (1975) presented noise stimuli, nonsense syllables, and monosyllabic words to babies, children, 
and adults. In all three groups they found greater left hemisphere $\mathrm{N}_{1}-\mathrm{P}_{2}$ amplitudes for both classes of verbal stimuli and greater right hemisphere $\mathrm{N}_{1}-\mathrm{P}_{2}$ amplitudes for the noise stimuli. Studies looking at hemispheric differences to speech and nonspeech stimuli when subjects were actively engaged in discrimination or detection tasks have been reported also. Friedman, Simson, Ritter, and Rapin (1975a) averaged potentials to human speech and human sounds when they comprised a "no task" condition, when they were "signal," and when they were "nonsignal" stimuli in a vigilance task. They reported that the amplitude of the left hemisphere $\mathrm{N}_{1}$ component of the evoked response to signal words was greater than the corresponding wave recorded from the right hemisphere. The asymmetry did not occur to signal sounds. No differences in $\mathrm{N}_{1}$ or $\mathrm{P}_{2}$ waves were obtained in the nonsignal or the no task conditions. Those authors did not report peak-to-peak $\mathrm{N}_{1}-\mathrm{P}_{2}$ amplitudes. In a second study, Friedman and his colleagues found larger left hemisphere $\mathrm{N}_{1}$ amplitudes to words which delivered task-relevant phonemic information (Friedman, Simson, Ritter, \& Rapin, 1975b). In both of Friedman's studies hemispheric asymmetries in the $\mathrm{P}_{3}$ waveform were inconsistent.

Matsumiya, Tagliasco, Lombroso, and Goodglass (1972) investigated the effect of the "meaningfulness" or "significance" of verbal and nonverbal stimuli to determine if this factor, rather than the verbal nature of the stimuli per se, could be responsible 
for the differential hemisphere response. As a measure of asymmetry they employed the ratio $\mathrm{R}=\mathrm{w}_{1} /\left(\mathrm{w}_{1}+\mathrm{w}_{\mathrm{r}}\right)$ where " $\mathrm{W}$ " refers to the peak-to-peak amplitude of the $\mathrm{N}_{1}-\mathrm{P}_{2}$ components and " $l$ " and " $r$ " refer to the left and right hemisphere responses, respectively. They reported that the response to meaningful words showed the greatest asymmetry, followed by that to meaningful noverbal stimuli. The latter, in turn, was larger than the asymetry occurring in the two nonmeaningful stimulus conditions. Even though greater asymmetries were observed during the meaningful conditions than in the others, most subjects did show a larger left hemisphere response in all conditions.

Galambos, Benson, Smith, Schulman-Galambos and Osier (1975) recently investigated the auditory evoked response to speech $(/ \mathrm{ba} /$; $/ \mathrm{pa} /)$ and tonal $(250 \mathrm{~Hz} ; 600 \mathrm{~Hz})$ stimuli and found no significant hemispheric differences in the mean amplitudes of the major components. In analyzing the output voltage at each digitized point along the time dimension of the waveforms, the general shape of the left hemisphere's response to the speech stimuli was found to differ substantially from that same hemisphere's response to the tones, particularly in the region of the $\mathrm{N}_{1}$ and $\mathrm{P}_{3}$ components. Those authors noted that although the group differences were not particularly large, some of the subjects had marked hemispheric asymmetries. The right hemisphere's responses to the speech and tone stimuli, however, were found to be quite similar to each other. 
Wood, Goff, and Day (1971) designed an experiment that allowed them to compare each hemisphere's response to a speechlike signal when the signal was part of a "linguistic" and a "nonlinguistic" discrimination task. In the former condition a subject had to make a phonemic discrimination between /ba/ and $/ d a /$; in the latter the stimuli differed in fundamental frequency, and thus required only a pitch discrimination (/ba/-low versus /ba/-high). The stimuli were such that /ba/ in the linguistic task was identical to the /ba/-low in the nonlinguistic discrimination task. Their data analysis consisted of a point by point comparison of the digitized output as described above. They found no difference between the shapes of the right hemisphere's responses to the common $/ \mathrm{ba} /$ in the two tasks, but the response obtained from the left side when subjects made the phonetic discrimination was significantly different at several time points from that hemisphere's response when only a pitch discrimination was made. Those authors suggested, therefore, that the left hemisphere responds differently to a stimulus during linquistic analysis than it does during nonlinguistic processing.

In 1975, Wood replicated the findings of his earlier study using different steady state formants and phonemes with different places of articulation. In addition, he included a condition in which subjects had to discriminate between two second formants isolated from acoustically different, but linguistucally similar stimuli. Since he found no differential left hemispheric response 
to the formants, he concluded that the previous finding with actual speech stimuli was related to the processing of the linguistic aspect of the stimuli and not simply the acoustic processing of the formant transitions of the stop consonants. At the present time there remain several inconsistencies in the existing data on hemispheric asymetries of auditory evoked potentials. Because of this, the cortical functions which underIie these asymmetries remain obscure. The fact that some investigators (e.g. Molfese et al., 1975) have observed a hemispheric asymmetry in the amplitudes of the evoked potential components when subjects were passive participants in an experiment suggests that the differential left hemisphere activity might reflect a physiological "1inguistic detector." This interpretation would be consistent with the report of hemispheric asymetries in babies (Molfese et al., 1975). The existence of such a detector which responds to phonemic transitions in a speech signal would explain the fact that asymmetries occur as early as 100 or 200 msec following stimulus onset, when much of the stimulus would not yet have been heard.

Other data, however, are inconsistent with the notion of a lateralized linguistic detector. For example, if such a device does exist then Friedman and his colleagues (Friedman et al., 1975a) should have observed significant hemispheric asymetries to words when they were of a nonsignal nature and when they comprised the no task condition just as they did when the words were signal stimuli. 
Galambos et al. (1975) showed that the waveforms recorded from the left hemisphere in response to speech and tonal stimuli were different while those recorded from the right hemisphere were not. That finding by itself supports a model for a lateralized detector in the left hemisphere. What is inconsistent, however, is that the asymmetry reported by Molfese et al. (1975) was manifest in the amplitudes of the major components $\left(\mathrm{N}_{1}-\mathrm{P}_{2}\right.$ amplitude) while in the Galambos study the hemispheric differences were not in amplitude measurements but in the differential shapes of their responses to speech and nonspeech stimuli.

In Wood's investigations (Wood, 1975; Wood et al., 1971), hemispheric responses were not compared for speech and nonspeech stimuli. Because of this, the data can be used neither to support nor refute the existence of a lateralized phonemic detector. The left hemisphere's response to a speech stimulus did differ, however, between phoneme discrimination and pitch discrimination. The data do suggest, therefore, the possibility of a lateralized center for phonemic discrimination as opposed to simple phonemic detection.

For an alternative explanation of Wood's data, one can borrow from Kinsbourne's (1970) model of selective attention. If, as Kinsbourne suggests, perceptual asymmetries result from a preparatory activation of the hemisphere responsible for analysis of an expected stimulus, then most of the evoked potential asymmetry 
data are confounded with this factor. For example, Friedman et al. (1975), employing human words and human sounds, presented these two types of stimuli to the subject in separate runs. Because the subjects were aware of the type of processing demanded by the task, differential activation of the hemispheres might have occurred. Similarly, Galambos and his colleagues employed speech and tones in their experiment but these, also, were presented in separate listings (Galambos et al., 1975).

The present investigation is designed to investigate further the phenomenon of evoked potential asymmetries as related to the left hemisphere's functional specialization for language processes. In addition, the present set of experiments is designed to investigate the role of expectancy or "cognitive set" on the auditory evoked potentials recorded from the two hemispheres. This can be done by presenting both speech and nonspeech stimuli within a single run while subjects are engaged in various tasks demanding phonetic and nonphonetic processing. If a lateralized cortical activation in preparation for verbal analysis of a stimulus does occur, then this effect should be manifest in the evoked response to a stimulus whenever a subject expects to make a phonetic discrimination, regardless of the actual nature of the stimulus presented. On the other hand, if subjects are involved in a discrimination task requiring nonphonetic (e.g. acoustic) analysis of speech or 
nonspeech stimuli, a hemispheric asymmetry should not be obtained, even if the evoking stimulus is verbal in nature. Thus, by averaging potentials to a speech and a nonspeech stimulus within the same series of stimuli, it can be determined if the data reported by Wood (Wood, 1975; Wood et al., 1971) were due to a differential left hemisphere activation in preparation for phonetic analysis or to the actual processing itself.

Finally, since speech and nonspeech stimuli will be employed and subjects will be discriminating stimuli belonging to one class (i.e. speech or nonspeech) from other stimuli of both classes, these experiments will allow for investigating possible differences among potentials when evoked by a relevant stimulus, an irrelevant stimulus belonging to the same class as the relevant stimulus, and an irrelevant stimulus belonging to the irrelevant class.

Ford, Roth, Dirks and Kopell (1973) reported that an irrelevant stimulus in the same sensory modality as a relevant one results in a smaller amplitude $\mathrm{P}_{3}$ than does the relevant stimulus, but that no difference in $\mathrm{N}_{2}$ occurs between the two stimuli. In contrast, waveforms evoked by stimuli in a modality other than the one of the relevant stimulus exhibit a small, if any, $\mathrm{N}_{2}$ and $\mathrm{P}_{3} \cdot$ Because of these findings, those authors suggested that the $\mathrm{N}_{2}$ component reflects preliminary processing of stimuli based on sensory modality and that the $\mathrm{P}_{3}$ component reflects the final decision process. Interpreting their data in terms of a neuxal template model (Hillyard, Squires, Bauer, \& Lindsay, 1971), they suggested that an irrelevant 
stimulus of the same modality caused a $\mathrm{P}_{3}$ wave because of a partial match to the template of the relevant stimulus. The intramodality auditory stimuli employed by Ford and her colleagues were not clearly described in their article. They used a click as one stimulus and a change in the level of a background noise as the other stimulus, but they did not report the duration of the click or the duration of the new noise level before it returned (if it did return) to the original "prestimulus" level. Also, they did not report the transition time from one noise level to the other. These stimulus parameters are important to the perception of the stimuli and without them it is difficult to evaluate the degree of "match" of one stimulus to a neural template of the other.

The present work involves procedures which use two speech stimuli and two nonspeech stimuli. Since these four auditory stimuli will be presented to subjects while they are engaged in tasks of stimulus relevance, the present study should serve as a more thorough test of the template mode. Since irrelevant stimuli will occur in both a relevant and an irrelevant class, a template model would predict an ordering of the $\mathrm{P}_{3}$ amplitudes as follows: the relevant stimulus should give the largest $\mathrm{P}_{3}$, followed by the irrelevant stimulus in the same class as the relevant stimulus, which, in turn, should give a Iarger $P_{3}$ than an irrelevant stimulus in an irrelevant class. 
If the $\mathrm{N}_{2}$ component reflects a decision of sensory modality as suggested by Ford, then no difference in the $\mathrm{N}_{2}$ amplitude should occur in the various conditions of stimulus relevance because all stimuli are auditory.

$\underline{\text { Summary }}$

There is a substantial body of research data, gathered from both clinical and nonclinical behavioral investigations, which support the phenomenon of specialization of function in the human brain. In addition, recent findings suggest that there are structural asymmetries in the cortex which parallel the functional differences.

Results of recent electrophysiological investigations suggest that the left hemisphere's specialization for langugage is reflected in the auditory evoked potentials elicited by speech and nonspeech stimuli, and during linguistic and nonlinguistic processing of speech stimuli. Because of several inconsistencies in the data, however, the precise nature of the effect as well as the actual processing mechanisms reflected in the asymmetries remain obscure. One purpose of the present work is to further investigate the evoked potential correlates of hemispheric specialization for language by recording auditory evoked potentials to speech and nonspeech stimuli from left and right temporo-parietal recording sites. The results of the present investigation should clarify certain issues regarding hemispheric asymmetries, with the following questions being addressed: How do left hemisphere responses compare to right hemisphere 
responses when the evoking stimulus is a speech signal and when it is a nonspeech signal? Are individual subjects' relative left-right asymmetries influenced by the verbal nature of a stimulus? Do subjects' responses to stimuli differ if they are evoked during a phonetic processing task as compared to a nonphonetic processing task? Finally, can the reported hemispheric asymmetries be explained as a preparatory activation of the left cortex due to the anticipation of phonetic processing of stimuli? A second issue to which the present work is addressed is one of electrophysiological correlates of stimulus relevance, and the results should broaden our understanding of the $\mathrm{N}_{2}$ and $\mathrm{P}_{3}$ components of the evoked potential with respect to their psychological correlates. For example, how do they relate to stimulus modality or stimulus similarity? Data from the present work should support or refute the interpretations that $\mathrm{N}_{2}$ reflects a decision regarding sensory modality of a stimulus and that $\mathrm{P}_{3}$ reflects a higher level match-mismatch detector. 
METHOD

\section{Subjects}

Subjects were six males and two females who were paid $\$ 2.00$ per hour for their participation in the study. Six subjects were recruited through an ad in the University of Florida student newspaper and two subjects were acquaintances of the investigator. Subjects'ages ranged from 19 years to 27 years, with a mean of approximately 23 years. All subjects had normal hearing and no history of hearing problems. All subjects were self-reported righthanders, with six of the eight having two parents who were also right-handed. The remaining two subjects had one right-handed and one left-handed parent.

Stimuli and Apparatus

Stimuli consisted of three natural speech consonant-vowel syllables and two nonspeech signals. The speech stimuli consisted of a low-pitched / ba/ having a fundamental frequency of $110 \mathrm{~Hz}$; a low-pitched /da/ also with a fundamental frequency of $110 \mathrm{~Hz}$; and a high-pitched / ba/ with a fundamental frequency of $144 \mathrm{~Hz}$. Each stimulus was uttered by an adult male and was $260 \mathrm{msec}$ in duration ( $\pm 4 \mathrm{msec})$. Fundamental frequency was measured from displays of the waveforms on a storage oscilloscope. 
The nonspeech stimuli were two square wave signals generated by a General Radio oscillator, Type 1313-A. One signal had a frequency of $110 \mathrm{~Hz}$ and the other a frequency of $144 \mathrm{~Hz}$. The nonspeech signals were shaped with an electronic switch (built at the Communication Sciences Laboratory of the University of Florida) to have a rise-fall time of $10 \mathrm{msec}$ and a duration of $260 \mathrm{msec}$.

Each stimulus was recorded onto a Sony two-channel stereo tape recorder, Model TC-353D and then dubbed onto an identical tape recorder in a prescribed order to make four series of stimuli, each on a separate tape.

Each of the four audiotapes presented a total of 256 stimuli: 64 presentations each of two speech stimuli and two nonspeech stimuli. The order of the four types of stimuli on each tape was randomized with two restrictions: first, each quarter of the tape (64 stimuli) contained an equal number (16) of the four stimuli; second, no more than two consecutive presentations of a given stimulus were allowed. These restrictions served to eliminate extreme sequences of stimuli which might have occurred by chance. The stimuli were recorded to have an interstimulus interval ranging from 3 secs to 6 secs. The orderings of the stimuli on the tapes are shown in Appendix A.

Two of the audio tapes contained the following four stimuli: the two nonspeech stimuli described above and the two low-pitched speech stimuli, /ba/ and /da/. These two tapes are referred to as 
phonetic tapes. Two phonetic tapes having different orderings of stimuli were employed to reduce the possibility of the subjects becoming familiar with the order of the stimuli.

The remaining two audio tapes contained the same two nonverbal stimuli, but the speech stimuli were the low-pitched /ba/ and the high-pitched /ba/. These tapes are referred to as the nonphonetic tapes. Again, two tapes were prepared to reduce subjects' familiarization with the order of the stimuli.

The low frequency and high frequency nonspeech stimuli are referred to throughout this paper as $\mathrm{T}_{1}$ and $\mathrm{T}_{2}$, respectively. The low / ba/ is referred to as $\mathrm{CV}_{1} . \mathrm{CV}_{2}$ refers to the remaining consonant-vowel stimuli, i.e., the low /da/ on the phonetic tapes and the high / ba/ on the nonphonetic tapes. Responses were averaged, using Digital's Basic Averager, to two evoking stimuli--CV $\mathrm{CV}_{1}$ and $\mathrm{T}_{1}$.

All stimuli were played on a Sony stereo tape recorder, Model TC-353D and presented to the subjects binaurally at $35 \mathrm{~dB}$ SL through Grason-Stadler TDH-39 earphones.

The evoked potentials were recorded using Grass silver-silver chloride electrodes and Grass electrode paste. The signals were amplified by calibrated Grass P511 amplifiers with a gain of 20,000 and half-amplitudes of $.1 \mathrm{~Hz}$ and $100 \mathrm{~Hz}$. Responses, stimuli, and synchronized pulses were all recorded onto separate channels of an Ampex FM tape recorder, Model Fr-100A. Averaging to $\mathrm{CV}_{1}$ was on line; averaging to $\mathrm{T}_{1}$ was off line, without further filtering. Averages were plotted on a Houston Omnigraphic X-Y plotter. 
Procedure

Subjects were tested individually over three separate sessions. They were seated comfortably in a reclining chair in a sound-proof IAC room. Recordings were taken from the vertex $(\mathrm{Cz})$ and the left and right temporo-parietal scalp locations (midway between $\mathrm{T} 3$ and $\mathrm{P} 3$ on the left and $\mathrm{T} 4$ and $\mathrm{P} 4$ on the right) after carefully preparing the site and applying the electrodes. The active sites were prepared by removing the hair at the location, rubbing briskly with acetone, rubbing the area with a small amount of paste, applying the electrodes and securing them with collodion. The removal of a few strands of hair at each site not only lowered the resistance but also guaranteed precise repositioning of the electrodes in subsequent sessions. The scalp locations were referenced to linked mastoids which were prepared similarly but with the electrodes secured with tape. The resistance between each pair of electrodes was kept below 5000 ohms and approximately equal (within 1000 ohms) for each pair. The subject was grounded with a midforehead electrode.

The same amplifier was used for the vertex recordings for all subjects. However, to control for any slight differences between the amplifiers used for the hemispheric recordings the leads from half the subjects were reversed so that each of the two remaining amplifiers received signals from the left hemisphere for half the subjects and the right hemisphere for the other half of the subjects. 
Each subject participated in eight conditions of stimulus relevance (four with the phonetic tapes and four with the nonphonetic tapes) and two control conditions (one with each type of tape). The ten conditions are summarized in Table 1 .

Prior to each condition of stimulus relevance, subjects were instructed as to the identity of the relevant stimulus for that trial. Subjects were told that they should listen selectively for the relevant stimulus and ignore all other stimuli. Half of the subjects responded, following the presentation of a relevant stimulus, by depressing with their index fingers a small button mounted on a box on the arm of their chair. The remaining half of the subjects responded with a similar button-push following all irrelevant stimuli and withheld a response following each presentation of the relevant stimulus. To avoid the contamination of the evoked response by muscle activity or motor potentials, subjects were instructed to wait from 1 to 2 secs following the stimulus before responding. In order to equalize the responses between the left and right hands, midway through each trial (following presentation of 128 stimuli) the experimenter switched the response box from one arm of the subject's chair to the other. Also during midtrial, the experimenter reversed the subject's headphones so that the effect of any possible difference between the earphones would be equalized.

In communicating to the subjects, the experimenter identified the relevant stimulus for a given trial as the "low tone," "high 
Table 1

Summary of Experimental Conditions

Task

Relevant

stimulus

Phonetic

Nonphonetic

Evoking stimulus: $\mathrm{CV}_{1}$

$$
\begin{aligned}
& \mathrm{CV}_{1} \\
& \mathrm{CV}_{2} \\
& \mathrm{~T}_{1} \\
& \mathrm{~T}_{2}
\end{aligned}
$$

Control

Evoking Stimulus: $\mathrm{T}_{1}$

$$
\begin{gathered}
\mathrm{T}_{1} \\
\mathrm{~T}_{2} \\
\mathrm{CV}_{1} \\
\mathrm{CV}_{2}
\end{gathered}
$$

Control

Note: Dependent variables in all conditions were amplitude and latency measures for $\mathrm{N}_{1}, \mathrm{P}_{2}, \mathrm{~N}_{2}$, and $\mathrm{P}_{3}$ components of the evoked potential recorded from vertex, left temporo-parietal, and right temporo-parietal sites. In every condition the subject was presented with a series of 256 stimuli (64 each of $\mathrm{CV}_{1}, \mathrm{CV}_{2}, \mathrm{~T}_{1}$, and $\mathrm{T}_{2}$ ) and potentials were recorded to $\mathrm{CV}_{1}$ and $\mathrm{T}_{1}$. 
tone," "low /ba/," "low /da/" (on phonetic tapes), or "high /ba/" (on nonphonetic tapes).

During the control conditions subjects were instructed to read and not attend to any of the stimuli. No response was required of the subjects during the control conditions.

Half the subjects were presented first with the phonetic tapes and second with the nonphonetic tapes. This order was reversed for the other subjects. To minimize the effects of fatigue or habituation on the evoked potentials, the temporal order of the stimulus relevance conditions was controlled. For a given subject the temporal position of the " $\mathrm{CV}_{1}$ relevant" condition, the " $\mathrm{T}_{1}$ relevant" condition, and the control condition were identical for phonetic and nonphonetic tape presentations and the $\mathrm{CV}_{2}$ relevant" and " $\mathrm{T}_{2}$ relevant" conditions were never more than one position removed for the two types of tapes. The actual orderings of conditions for the subjects are shown in Appendix B.

Each experimental session lasted from two to three hours: approximately 30 minutes for application of electrodes and about 90 minutes to 2 hours of actual recording. Subjects were given a 15 to 20 minute break following the first 60 minutes of recording. Prior to each recording session subjects were instructed to remain very still, not to swallow, and not to blink during the recording sessions. If it was absolutely necessary for them to do one of these things they were to do it at the same time they pushed 
the button (between the presentation of stimuli). During the conditions of stimulus relevance subjects fixated on a picture or an object so that eye potentials would not contaminate the evoked responses. 
RESULTS

Auditory evoked potentials to a speech stimulus (CV $)_{1}$ and a nonspeech stimulus $\left(\mathrm{T}_{1}\right)$ were recorded from vertex, left temporoparietal, and right temporo-parietal locations. The data were analyzed for topographical differences, effects of phonetic processing, and effects of stimulus relevance. Peak amplitudes of the $\mathrm{N}_{1}, \mathrm{P}_{2}, \mathrm{~N}_{2}$, and $\mathrm{P}_{3}$ components, the $\mathrm{N}_{1}-\mathrm{P}_{2}$ peak-to-peak amplitude, and the latencies of the various components were measured. The 6 msec following stimulus onset was used as the baseline from which the peak amplitudes were measured. Components were defined as follows: $N_{1}$ was the most negative point occurring between 80 and 140 msec following stimulus onset; $P_{2}$ was the most positive point occurring between 170 and $240 \mathrm{msec}$ following stimulus onset; $P_{3}$ was the most positive point between 260 and 420 msec poststimulus onset; and $\mathrm{N}_{2}$ was the most negative point occurring between $\mathrm{P}_{2}$ and $\mathrm{P}_{3}$.

To determine the significance of the differences among mean amplitudes or latencies of the components recorded from the three locations during phonetic and nonphonetic processing tasks, repeated measures analyses of variance were computed for various condition of stimulus relevance. Because of the design of the study, for each evoking stimulus there is one condition in which the evoking stimulus 
is the relevant stimulus (referred to as $R / R$ ); one condition in which the evoking stimulus is an irrelevant stimulus but of the same class (i.e. speech or nonspeech) as the relevant stimulus $(I / R)$; and two conditions in which the evoking stimulus is irrelevant and of the irrelevant class (I/I). The two I/I conditions for the $\mathrm{CV}_{1}$ evoking stimulus are the $\mathrm{T}_{1}$ relevant and the $\mathrm{T}_{2}$ relevant conditions; for the $\mathrm{T}_{1}$ evoking stimulus the two $\mathrm{I} / \mathrm{I}$ conditions are the $\mathrm{CV}_{1}$ relevant and $\mathrm{CV}_{2}$ relevant condtions. In order to simplify the analyses and eliminate redundant information, the second I/I condition of stimulus relevance was excluded. This leaves a total of four conditions: $R / R, I / R, I / I$, and control. For the $\mathrm{CV}_{1}$ evoking stimulus these are the $\mathrm{CV}_{1}$ relevant, $\mathrm{CV}_{2}$ relevant, $\mathrm{T}_{1}$ relevant, and Control; for the $\mathrm{T}_{1}$ evoking stimulus these are the $\mathrm{T}_{1}$ relevant, $\mathrm{T}_{2}$ relevant, $\mathrm{CV}_{1}$ relevant, and Control conditions.

When appropriate, the Sign test (Siegel, 1956) was used in addition, to determine the significance of the number of persons showing a particular response characteristic. The findings of these analyses are reported below.

\section{Topographical Effects}

Amplitude measures. Peak amplitudes of the $\mathrm{N}_{1}$ and $\mathrm{P}_{2}$ waves, as well as the peak-to-peak $\mathrm{N}_{1}-\mathrm{P}_{2}$ amplitudes were substantially larger at the vertex than they were at the lateral sites. This effect is illustrated in Figures 1 and 2, which show the evoked 
Relevant

Stimulus

$\mathrm{CV}_{1}$

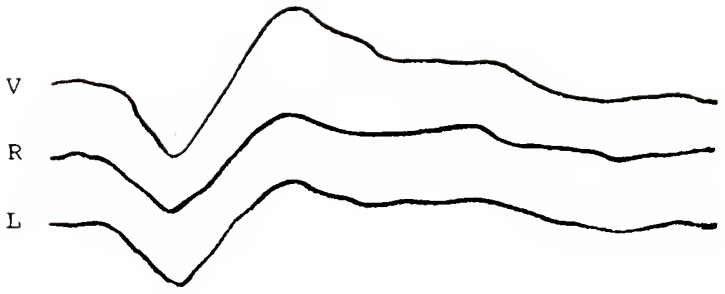

$\mathrm{CV}_{2}$

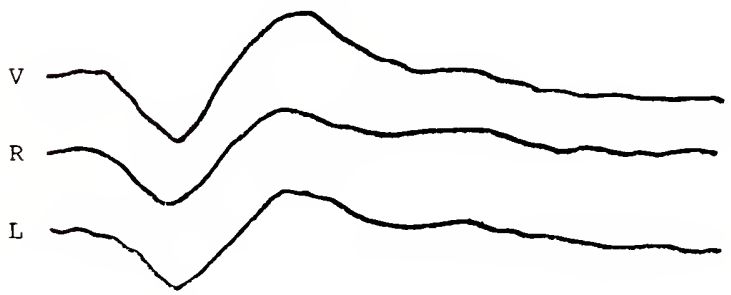

$\mathrm{T}_{1}$

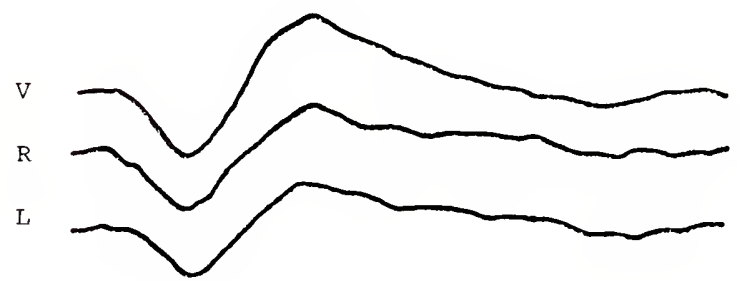

Control

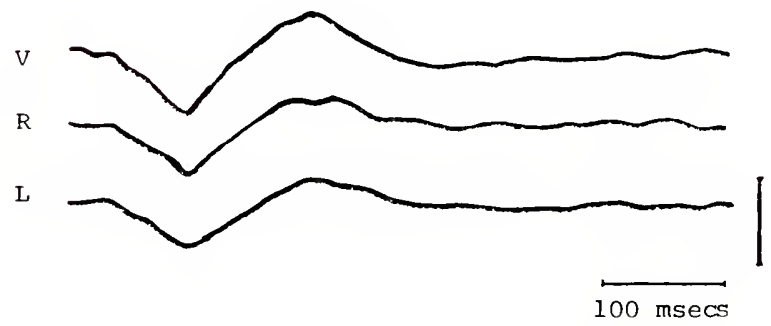

Figure 1. Averaged evoked potentials to $\mathrm{CV}_{1}$ stimulus recorded from vertex (V), left (L), and right (R) temporo-parietal sites during various conditions. Each potential is a composite of eight subjects. Calibration $=10$ microvolts. 
Relevant Stimulus

$\mathrm{T}_{\mathrm{I}}$

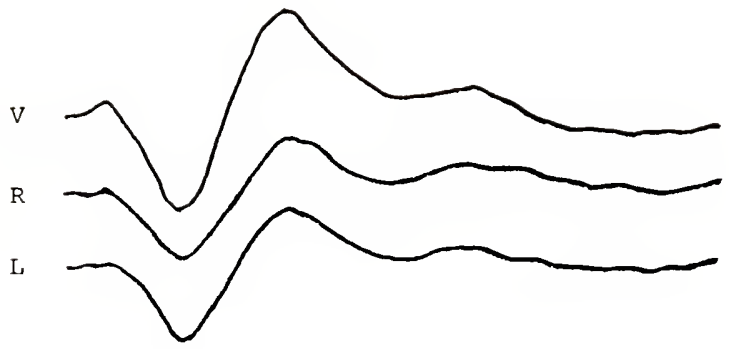

$\mathrm{T}_{2}$

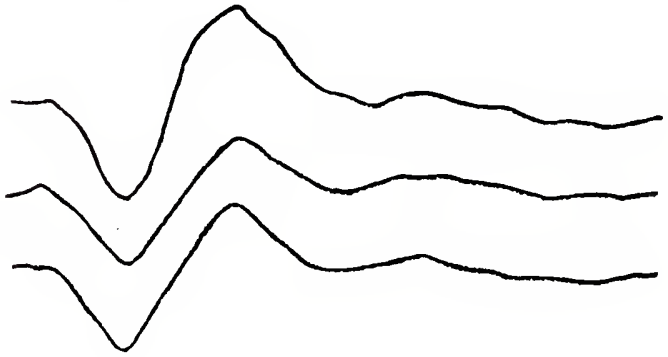

$\mathrm{CV}_{1}$

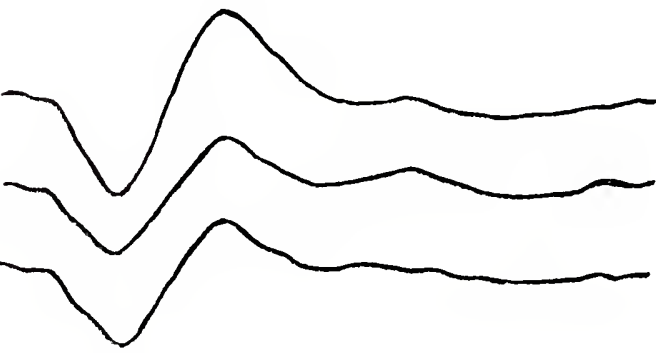

Control

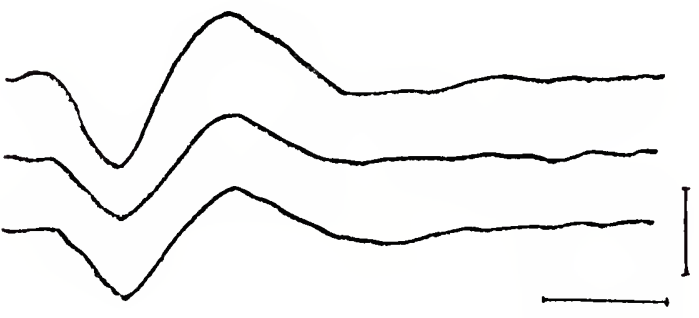

$100 \mathrm{msecs}$

Figure 2. Averaged evoked potentials to $\mathrm{T}_{1}$ stimulus recorded from vertex (V), left (L), and right (R), temporo-parietal sites during various conditions. Each potential is a composite of eight subjects. Calibration $=10$ microvolts. 
potentials recorded from vertex, left temporo-parietal and right temporo-parietal locations during each condition of stimulus relevance. Figures 1 and 2 show the potentials evoked by $\mathrm{CV}_{1}$ and ' 1 ' respectively. Each waveform in the figures represents a composite of responses from all subjects in both phonetic and nonphonetic conditions. The actual values of the amplitudes of the various components for each location are presented in Table 2 . The differences between the vertex responses and the temporoparietal responses are significant at the .01 level of probability for every condition of stimulus relevance as well as for the control conditions. Results of Tukey's a posteriori test (Kirk, 1968) comparing the mean amplitudes of the $\mathrm{N}_{1}, \mathrm{P}_{2}$, or $\mathrm{N}_{1}-\mathrm{P}_{2}$ components recorded from the left location with those of the riaht location were all nonsignificant. No significant topographical differences were obtained among the three recording sites for the $\mathrm{N}_{2}$ or $\mathrm{P}_{3}$ components in any condition.

Although the overall mean differences between the $\mathrm{N}_{1}, \mathrm{P}_{2}$, and $\mathrm{N}_{1}-\mathrm{P}_{2}$ amplitudes between the left and right hemispheres did not differ significantly, in most conditions the majority of persons did show asymmetries with larger amplitudes on the left. Table 3 presents the number of persons in each condition whose left hemisphere amplitudes were larger than the right hemisphere amplitudes. Although the majority of persons did show a larger left hemisphere response, particularly when $\mathrm{CV}_{1}$ was the relevant 
Table 2

Mean Amplitudes (microvolts) for Major Components of Evoked Responses Recorded from Three Locations

Evoking stimulus

\begin{tabular}{|c|c|c|c|c|c|c|c|c|}
\hline \multirow{2}{*}{$\begin{array}{c}\text { Com- } \\
\text { ponent }\end{array}$} & \multirow{2}{*}{$\begin{array}{l}\text { Relevant } \\
\text { Stimulus }\end{array}$} & \multicolumn{3}{|c|}{$\mathrm{CV}_{1}$} & \multirow{2}{*}{$\begin{array}{l}\text { Relevant } \\
\text { Stimulus }\end{array}$} & \multicolumn{3}{|c|}{$\mathrm{T}_{1}$} \\
\hline & & $v^{a}$ & I & $R$ & & V & $\mathrm{L}$ & $\mathrm{R}$ \\
\hline \multirow[t]{4}{*}{$\mathrm{N}_{1}$} & $\mathrm{CV}_{1}$ & 10.5 & 8.5 & 8.1 & $\mathrm{~T}_{1}$ & 12.3 & 9.7 & 9.5 \\
\hline & $\mathrm{CV}_{2}$ & 9.4 & 8.3 & 7.4 & $\mathrm{~T}_{2}$ & 13.4 & 10.4 & 10.1 \\
\hline & $\mathrm{T}_{1}$ & 9.6 & 7.7 & 7.7 & $\mathrm{CV}_{1}$ & 13.2 & 10.3 & 9.5 \\
\hline & Control & 9.6 & 8.2 & 7.9 & Control & 12.1 & 10.0 & 8.9 \\
\hline \multirow[t]{4}{*}{$\mathrm{P}_{2}$} & $\mathrm{CV}_{1}$ & 10.1 & 6.9 & 6.5 & $\mathrm{~T}_{1}$ & 13.1 & 8.3 & 7.7 \\
\hline & $\mathrm{CV}_{2}$ & 9.1 & 6.2 & 6.3 & $\mathrm{~T}_{2}$ & 12.5 & 8.7 & 7.7 \\
\hline & $\mathrm{T}_{1}$ & 10.5 & 6.7 & 6.6 & $\mathrm{CV}_{1}$ & 11.9 & 7.6 & 7.3 \\
\hline & Control & 6.2 & 4.1 & 4.3 & Control & 9.0 & 5.7 & 5.7 \\
\hline \multirow[t]{4}{*}{$\mathrm{N}_{1}-\mathrm{P}_{2}$} & $\mathrm{CV}_{\mathrm{I}}$ & 20.6 & 15.4 & 14.6 & $\mathrm{~T}_{1}$ & 25.4 & 18.0 & 17.2 \\
\hline & $\mathrm{CV}_{2}$ & 18.5 & 14.5 & 13.7 & $\mathrm{~T}_{2}$ & 25.9 & 19.1 & 17.8 \\
\hline & $\mathrm{T}_{1}$ & 20.1 & 14.4 & 14.3 & $\mathrm{CV}_{1}$ & 25.1 & 17.9 & 16.8 \\
\hline & Control & 15.8 & 12.3 & 12.2 & Control & 21.1 & 15.7 & 14.6 \\
\hline
\end{tabular}


Table 2 - continued

Evoking Stimulus

\begin{tabular}{cccccccccc}
\multirow{2}{c}{$\begin{array}{c}\text { Com- } \\
\text { ponent }\end{array}$} & $\begin{array}{c}\text { Relevant } \\
\text { Stimulus }\end{array}$ & $\mathrm{V}^{\mathrm{a}}$ & $\mathrm{L}$ & $\mathrm{R}$ & $\begin{array}{c}\mathrm{CV}_{1} \\
\text { Relevant } \\
\text { Stimulus }\end{array}$ & $\mathrm{V}$ & $\mathrm{L}$ & $\mathrm{R}$ \\
\hline $\mathrm{N}_{2}$ & $\mathrm{CV}_{1}$ & .7 & .5 & .8 & $\mathrm{~T}_{1}$ & .7 & -.1 & -1.5 \\
& $\mathrm{CV}_{2}$ & -.2 & -.2 & .1 & $\mathrm{~T}_{2}$ & -1.9 & -1.1 & -1.0 \\
& $\mathrm{~T}_{1}$ & .9 & .7 & .7 & $\mathrm{CV}_{1}$ & -1.1 & -1.0 & -.8 \\
& $\mathrm{CV}_{1}$ & 4.2 & 4.5 & 4.9 & $\mathrm{~T}_{1}$ & 4.8 & 3.4 & 4.4 \\
& $\mathrm{CV}_{2}$ & 2.1 & 2.3 & 3.2 & $\mathrm{~T}_{2}$ & 3.3 & 2.4 & 2.5 \\
& $\mathrm{~T}_{1}$ & 3.5 & 3.6 & 3.9 & $\mathrm{CV}_{1}$ & 1.4 & 2.2 & 3.4 \\
\hline
\end{tabular}

Note: A positive amplitude for $\mathrm{N}_{2}$ means that the most negative peak between $\mathrm{P}_{2}$ and $\mathrm{P}_{3}$ was above the baseline.

$\mathrm{a}_{\mathrm{V}}=$ Vertex; L=Left Temporo-Parietal; $\mathrm{R}=\mathrm{Right}$ Temporo-Parietal. 
Table 3

Number of Persons Having Greater Left Hemisphere Amplitudes for Various Components

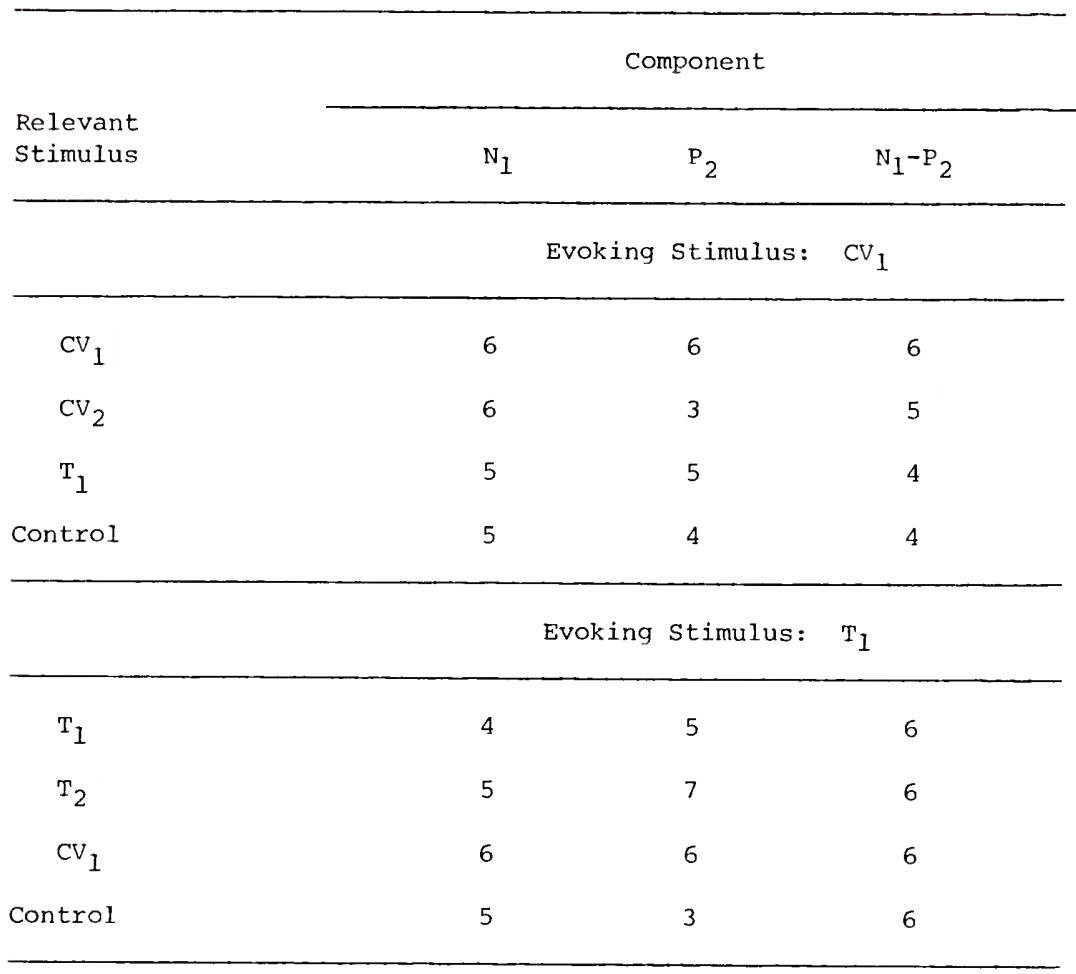


stimulus, in only one condition did the sign test on this frequency data actually reach significance. This condition is the one in which $\mathrm{T}_{2}$ was relevant and the evoking stimulus was $\mathrm{T}_{1}$. In this condition a significant number of persons (seven out of eight) had a larger $\mathrm{P}_{2}$ amplitude on the left than on the right.

To provide an indication of the degree of asymmetry which occurred for each subject, the procedure described by Matsumiya et al. (1972) and later employed by others (Friedman et al., 1975a; Molfese et al., 1975) was used. This procedure entails calculating R-values for each subject by dividing the left hemisphere amplitude by the sum of the amplitudes of the left and right hemispheres. Thus, an R-value greater than .5 indicates a larger left hemisphere $\mathrm{N}_{1}-\mathrm{P}_{2}$ response while a value less than .5 indicates a larger right hemisphere response. R-values for each subject are shown in the upper half of Figure 3. Each R-value shown is a composite of all conditions.

Since R-values are simply ratios, however, they do not provide a clear indication of the degree of asymmetry. For example, a 2 microvolt difference between the left and right amplitudes would yield substantially larger R-values if the amplitudes were around 5 microvolts than if they were around 20 microvolts. Also, a person whose left hemisphere amplitude is 3 microvolts larger than the right but whose amplitudes are 20 and 17 microvolts for the left and right hemispheres, respectively, would have an R-value of .55 while a second person having only a 1 microvolt difference 
EVOKING

STIMULUS
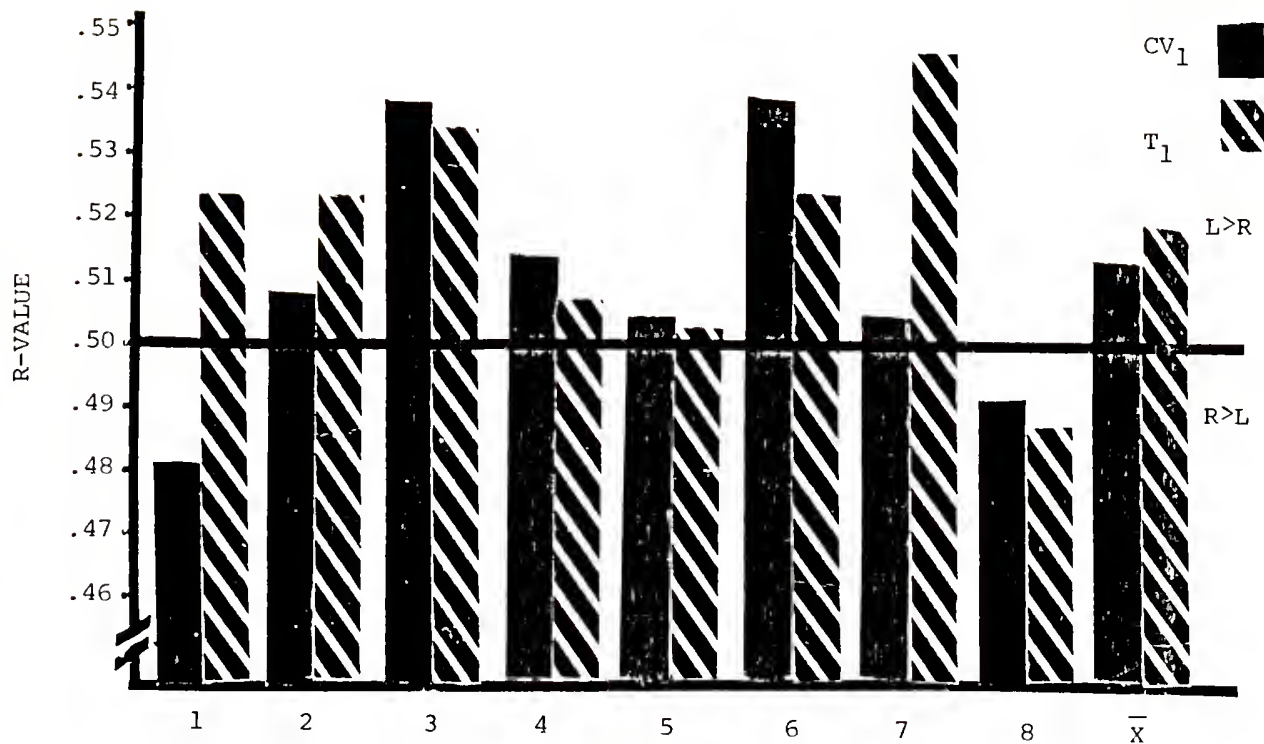

SUBJECT

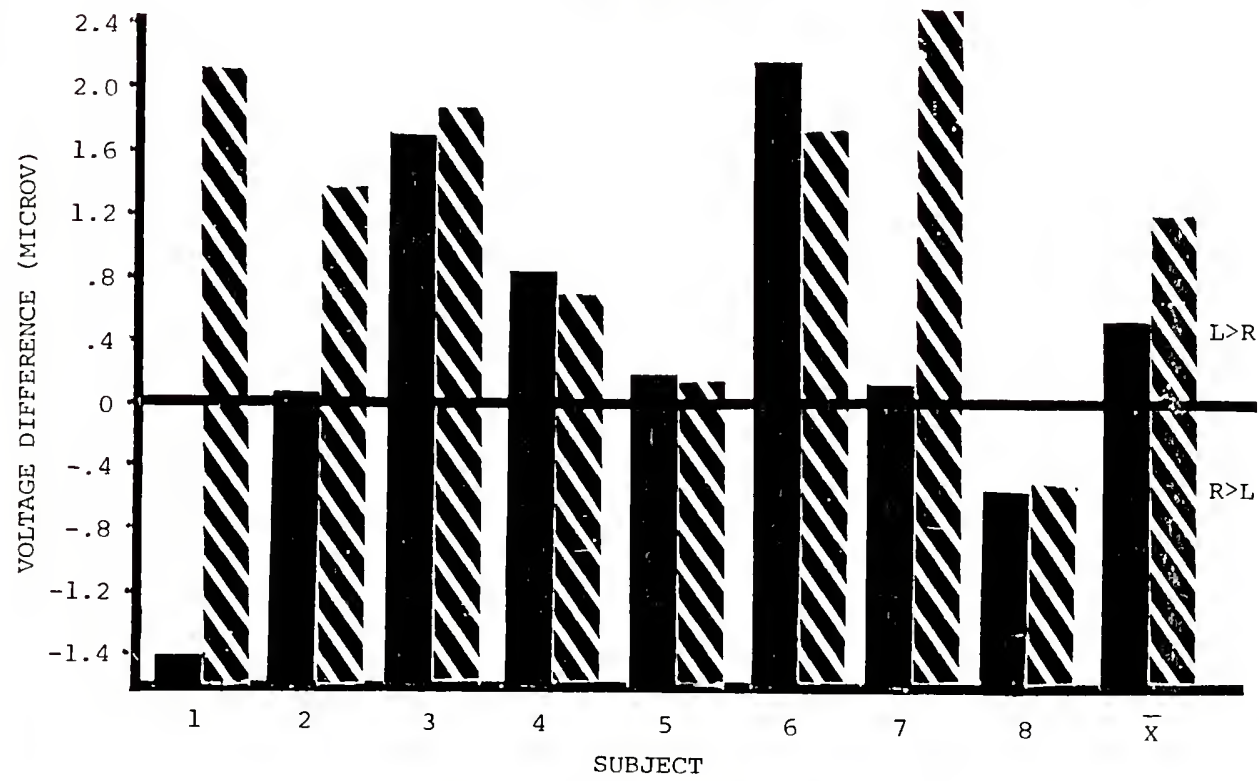

Figure 3. R-values (upper) and hemispheric voltage differences (lower) for all subjects across all conditions. A larger left hemisphere amplitude is represented by an R-value $>.5$ or a positive voltage difference. 
would have the same ratio if his left and right amplitudes were about 7 and 6 microvolts, respectively. Because of this fact, it was desirable to calculate actual magnitudes of the hemisphere differences as indices of asymmetries in addition to the R-values. Thus, shown in the lower half of Figure 3 are the differences between the mean left hemisphere $\mathrm{N}_{1}-\mathrm{P}_{2}$ amplitude across all conditions and the mean right hemisphere $\mathrm{N}_{1}-\mathrm{P}_{2}$ amplitude across all conditions. It is comforting to see that the two halves of the figure agree fairly well with respect to individual subjects' asymmetries, but it is the lower half which provides information regarding the absolute magnitude of each person's asymmetry.

Latency measures. In general, the latencies for the $\mathrm{N}_{1}$ and $\mathrm{P}_{2}$ components of the responses recorded from the vertex were slightly shorter than those recorded from the lateral sites. Across all conditions the mean $\mathrm{N}_{1}$ latency for vertex, left, and right temporoparietal locations are 107, 108, and $109 \mathrm{msec}$, respectively, when $\mathrm{CV}_{1}$ was the evoking stimulus; and 106, 109, and $110 \mathrm{msec}$ when $\mathrm{T}_{1}$ was the evoking stimulus. The corresponding latencies for $\mathrm{P}_{2}$ are 200, 204, and $205 \mathrm{msec}$ for $\mathrm{CV}_{1}$; and 190, 194, and $195 \mathrm{msec}$ for $\mathrm{T}_{1}$. Latencies for individual conditions of stimulus relevance are presented in Table 4. The analyses of variance failed to show any significant differences in the mean latencies for the three recording sites, but it is notable that in no condition were the mean $\mathrm{N}_{1}$ or $\mathrm{P}_{2}$ latencies for either of the temporo-parietal sites less than that for the vertex. 
Table 4

Mean Latencies (msec) for Major Components

of Evoked Responses Recorded from Three Locations

Evoking Stimulus

\begin{tabular}{|c|c|c|c|c|c|c|c|c|}
\hline \multirow{2}{*}{$\begin{array}{l}\text { Com- } \\
\text { ponent }\end{array}$} & \multirow{2}{*}{$\begin{array}{l}\text { Relevant } \\
\text { Stimulus }\end{array}$} & \multicolumn{3}{|c|}{$\mathrm{CV}_{1}$} & \multirow{2}{*}{$\begin{array}{l}\text { Relevant } \\
\text { Stimulus }\end{array}$} & \multicolumn{3}{|c|}{$\mathrm{T}_{1}$} \\
\hline & & $\mathrm{v}^{\mathrm{a}}$ & . L & $\mathrm{R}$ & & v & $\mathrm{L}$ & $\mathrm{R}$ \\
\hline \multirow[t]{4}{*}{$\mathrm{N}_{1}$} & $\mathrm{CV}_{1}$ & 107 & 107 & 109 & $\mathrm{~T}_{I}$ & 106 & 108 & 107 \\
\hline & $\mathrm{CV}_{2}$ & 108 & 110 & 110 & $\mathrm{~T}_{2}$ & 107 & 109 & 110 \\
\hline & $\mathrm{T}_{1}$ & 106 & 107 & 108 & $\mathrm{CV}_{1}$ & 106 & 109 & 110 \\
\hline & Control & 106 & 107 & 107 & Control & 106 & 108 & 111 \\
\hline \multirow[t]{4}{*}{$\mathrm{P}_{2}$} & $\mathrm{CV}_{1}$ & 201 & 203 & 204 & $\mathrm{~T}_{1}$ & 189 & 192 & 190 \\
\hline & $\mathrm{CV}_{2}$ & 199 & 201 & 204 & $\mathrm{~T}_{2}$ & 188 & 193 & 196 \\
\hline & $\mathrm{T}_{1}$ & 201 & 205 & 208 & $\mathrm{CV}_{1}$ & 190 & 198 & 196 \\
\hline & Control & 200 & 208 & 204 & Control & 192 & 194 & 197 \\
\hline \multirow[t]{3}{*}{$\mathrm{N}_{2}$} & $\mathrm{CV}_{1}$ & 278 & 274 & 272 & $\mathrm{~T}_{1}$ & 276 & 278 & 279 \\
\hline & $\mathrm{CV}_{2}$ & 290 & 287 & 282 & $\mathrm{~T}_{2}$ & 285 & 279 & 282 \\
\hline & $\mathrm{T}_{1}$ & 292 & 288 & 283 & $\mathrm{CV}_{1}$ & 284 & 277 & 276 \\
\hline \multirow[t]{3}{*}{$P_{3}$} & $\mathrm{CV}_{\mathrm{I}}$ & 325 & 335 & 338 & $\mathrm{~T}_{1}$ & 328 & 336 & 335 \\
\hline & $\mathrm{CV}_{2}$ & 320 & 323 & 326 & $\mathrm{~T}_{2}$ & 334 & 334 & 339 \\
\hline & $\mathrm{T}_{1}$ & 326 & 327 & 326 & $\mathrm{CV}_{1}$ & 324 & 329 & 329 \\
\hline
\end{tabular}

$\mathrm{a}_{\mathrm{V}}=$ Vertex; L=Left Temporo-Parietal; R=Right Temporo-Parietal. 
The mean latencies for the $\mathrm{P}_{3}$ component of the evoked potentials were also shorter for the vertex than for the left or right locations, but these differences also failed to reach statistical significance. In contrast to the other components, the latencies of the $\mathrm{N}_{2}$ wave were generally longer when recorded from the vertex. The latency values for $\mathrm{N}_{2}$ and $\mathrm{P}_{3}$ are shown also in Table 4 .

No consistent latency differences occurred between the left and right recording sites for any of the components.

Phonetic versus Nonphonetic Tape Effects

Amplitude measures. The mean amplitude of the various components of potentials evoked by $\mathrm{CV}_{1}$ and $\mathrm{T}_{1}$ on the phonetic tapes and the nonphonetic tapes are shown in Table 5 for each condition of stimulus relevance. The values in that table represent the mean amplitudes for the three recording sites across all eight subjects. The only differences that proved to be significant occurred during the condition in which subjects were discriminating the $\mathrm{CV}_{1}$ stimulus from the other three stimuli. In that condition, the amplitude of the $\mathrm{N}_{1}$ component was significantly larger during phonetic processing of the speech stimuli ( 10.3 microvolts) than during nonphonetic processing of them $(7.8$ microvolts). This difference is significant at the .05 level of probability, $F(1,7)=10.90$.

As described under the procedure section of this paper, the evoked response to the nonspeech stimulus, $\mathrm{T}_{1}$, was averaged during the same series of stimulus presentations as was the response to 
Table 5

Mean Amplitudes (microvolts) for Major Components of Potentials Evoked by Stimuli on Phonetic and Nonphonetic Tapes

Evoking Stimulus

\begin{tabular}{|c|c|c|c|c|c|c|}
\hline \multirow{2}{*}{$\begin{array}{l}\text { Com- } \\
\text { Ponent }\end{array}$} & \multirow{2}{*}{$\begin{array}{l}\text { Relevant } \\
\text { Stimulus }\end{array}$} & \multicolumn{2}{|c|}{$\mathrm{CV}_{1}$} & \multirow{2}{*}{$\begin{array}{l}\text { Relevant } \\
\text { Stimulus }\end{array}$} & \multicolumn{2}{|c|}{$\mathrm{T}_{1}$} \\
\hline & & $\mathrm{p}^{\mathrm{a}}$ & $\mathrm{N}$ & & P & $\mathrm{N}$ \\
\hline \multirow[t]{4}{*}{$\mathrm{N}_{1}$} & $\mathrm{CV}_{1}$ & 10.3 & 7.8 & $\mathrm{~T}_{1}$ & 10.5 & 10.5 \\
\hline & $\mathrm{CV}_{2}$ & 8.1 & 8.7 & $\mathrm{~T}_{2}$ & 12.0 & 10.5 \\
\hline & $\mathrm{T}_{1}$ & 8.3 & 8.5 & $\mathrm{CV}_{1}$ & 11.0 & 10.9 \\
\hline & Control & 9.7 & 7.3 & Control & 10.6 & 10.1 \\
\hline \multirow[t]{4}{*}{$\mathrm{P}_{2}$} & $\mathrm{CV}_{1}$ & 6.6 & 9.0 & $\mathrm{~T}_{1}$ & 10.1 & 9.6 \\
\hline & $\mathrm{CV}_{2}$ & 7.4 & 7.0 & $\mathrm{~T}_{2}$ & 9.1 & 10.2 \\
\hline & $\mathrm{T}_{1}$ & 8.2 & 7.7 & $\mathrm{CV}_{1}$ & 9.1 & 8.8 \\
\hline & Control & 3.9 & 5.8 & Control & 6.2 & 7.4 \\
\hline \multirow[t]{4}{*}{$\mathrm{N}_{1}-\mathrm{P}_{2}$} & $\mathrm{CV}_{1}$ & 16.9 & 16.8 & $\mathrm{~T}_{1}$ & 20.6 & 20.1 \\
\hline & $\mathrm{CV}_{2}$ & 15.5 & 15.7 & $\mathrm{~T}_{2}$ & 21.1 & 20.7 \\
\hline & $\mathrm{T}_{1}$ & 16.5 & 16.2 & $\mathrm{CV}_{1}$ & 20.1 & 19.7 \\
\hline & Control & 13.6 & 13.1 & Control & 16.8 & 17.5 \\
\hline
\end{tabular}


Table 5 - continued

\begin{tabular}{|c|c|c|c|c|c|c|}
\hline \multirow{3}{*}{$\begin{array}{l}\text { Com- } \\
\text { ponent }\end{array}$} & & & \multicolumn{4}{|c|}{ Evoking Stimulus } \\
\hline & \multirow{2}{*}{$\begin{array}{l}\text { Relevant } \\
\text { Stimulus }\end{array}$} & \multicolumn{2}{|c|}{$\mathrm{CV}_{1}$} & \multirow{2}{*}{$\begin{array}{l}\text { Relevant } \\
\text { Stimulus }\end{array}$} & \multicolumn{2}{|c|}{$\mathrm{T}_{1}$} \\
\hline & & $\mathrm{p}^{\mathrm{a}}$ & $\mathrm{N}$ & & P & $\mathrm{N}$ \\
\hline \multirow[t]{3}{*}{$\mathrm{N}_{2}$} & $\mathrm{CV}_{1}$ & 0.0 & 1.3 & $\mathrm{~T}_{1}$ & 1.0 & -1.6 \\
\hline & $\mathrm{CV}_{2}$ & 0.3 & -0.5 & $\mathrm{~T}_{2}$ & -2.3 & -0.4 \\
\hline & $\mathrm{T}_{1}$ & 1.4 & 0.1 & $\mathrm{CV}_{1}$ & -0.8 & -1.2 \\
\hline \multirow[t]{3}{*}{$\mathrm{P}_{3}$} & $\mathrm{CV}_{1}$ & 4.0 & 5.0 & $\mathrm{~T}_{1}$ & 4.9 & 3.8 \\
\hline & $\mathrm{CV}_{2}$ & 2.4 & 2.6 & $\mathrm{~T}_{2}$ & 2.7 & 2.8 \\
\hline & $\mathrm{T}_{1}$ & 4.5 & 2.8 & $\mathrm{CV}_{1}$ & 2.8 & 1.9 \\
\hline
\end{tabular}

Note: A positive amplitude for $\mathrm{N}_{2}$ means that the most negative peak between $\mathrm{P}_{2}$ and $\mathrm{P}_{3}$ was above the baseline.

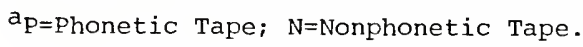


$\mathrm{CV}_{1}$; yet there was virtually no difference between the $\mathrm{N}_{1}$ amplitudes of potentials evoked by $\mathrm{T}_{1}$ on the phonetic tapes and on the nonphonetic tapes. The mean amplitudes are 11.0 and 10.9 microvolts, respectively, $\underline{E}(1,7)=.02, \underline{p}>.05$.

In the same condition, a similar effect occurred with the amplitude measure of the $\mathrm{P}_{2}$ component, but in the opposite direction. During phonetic processing the mean peak amplitude of the response to $\mathrm{CV}_{1}$ was 6.6 microvolts and during nonphonetic processing it was 9.0 microvolts, $\underline{F}(1,7)=10.51, \underline{p}<05$. The corresponding amplitudes of the potentials evoked by $\mathrm{T}_{1}$ are 9.1 and 8.8 microvolts, $\underline{F}(1,7)=.15, \underline{p}>0.05$.

None of the other components of the potentials were found to be significantly different when evoked by stimuli on the phonetic tapes as compared to when evoked by stimuli on the nonphonetic tapes.

Latency measures. Latencies of components elicited by stimuli on the two types of tapes are shown in Table 6 . The only significant difference between the phonetic and nonphonetic processing tasks was in $\mathrm{N}_{1}$ latency and occurred for the $\mathrm{CV}_{1}$ evoking stimulus when $\mathrm{CV}_{1}$ was the relevant stimulus. Across all subjects, the mean latencies for $\mathrm{N}_{1}$ are 110 and $105 \mathrm{msecs}$ for the two tasks, respectively, $\underline{F}(1,7)=6.23, p<.05$. In contrast, the corresponding latencies for responses evoked by $\mathrm{T}_{1}$ were not significantly different from each other, $\underline{E}(1,7)=.44, \underline{p}>05$. These values are 109 msecs and 108 msecs for phonetic and nonphonetic tapes, respectively. 
Table 6

Mean Latencies (msec) for Major Components of Potentials Evoked by Stimuli on Phonetic and Nonphonetic Tapes

Evoking Stimulus

\begin{tabular}{|c|c|c|c|c|c|c|}
\hline \multirow{2}{*}{$\begin{array}{l}\text { Com- } \\
\text { ponent }\end{array}$} & \multirow{2}{*}{$\begin{array}{l}\text { Relevant } \\
\text { Stimulus }\end{array}$} & \multicolumn{2}{|c|}{$\mathrm{CV}_{1}$} & \multirow{2}{*}{$\begin{array}{l}\text { Relevant } \\
\text { Stimulus }\end{array}$} & \multicolumn{2}{|r|}{$\mathrm{T}_{1}$} \\
\hline & & $\mathrm{p}^{\mathrm{a}}$ & $\mathrm{N}$ & & $\mathrm{P}$ & $\mathrm{N}$ \\
\hline \multirow[t]{4}{*}{$\mathrm{N}_{1}$} & $\mathrm{CV}_{1}$ & 110 & 105 & $\mathrm{~T}_{1}$ & 108 & 106 \\
\hline & $\mathrm{CV}_{2}$ & 105 & 113 & $\mathrm{~T}_{2}$ & 107 & 110 \\
\hline & $\mathrm{T}_{1}$ & 105 & 109 & $\mathrm{CV}_{1}$ & 109 & 108 \\
\hline & Control & 106 & 107 & Control & 110 & 107 \\
\hline \multirow[t]{4}{*}{$\mathrm{P}_{2}$} & $\mathrm{CV}_{1}$ & 203 & 202 & $\mathrm{~T}_{1}$ & 192 & 188 \\
\hline & $\mathrm{CV}_{2}$ & 196 & 207 & $\mathrm{~T}_{2}$ & 190 & 194 \\
\hline & $\mathrm{T}_{1}$ & 205 & 205 & $\mathrm{CV}_{1}$ & 195 & 194 \\
\hline & Control & 206 & 202 & Control & 196 & 193 \\
\hline \multirow[t]{3}{*}{$\mathrm{N}_{2}$} & $\mathrm{CV}_{1}$ & 274 & 276 & $\mathrm{~T}_{1}$ & 276 & 274 \\
\hline & $\mathrm{CV}_{2}$ & 288 & 285 & $\mathrm{~T}_{2}$ & 281 & 284 \\
\hline & $\mathrm{T}_{1}$ & 285 & 290 & $\mathrm{CV}_{1}$ & 280 & 278 \\
\hline \multirow[t]{3}{*}{$\mathrm{P}_{3}$} & $\mathrm{CV}_{1}$ & 334 & 332 & $\mathrm{~T}_{1}$ & 327 & 339 \\
\hline & $\mathrm{CV}_{2}$ & 319 & 328 & $\mathrm{~T}_{2}$ & 335 & 337 \\
\hline & $\mathrm{T}_{1}$ & 323 & 330 & $\mathrm{CV}_{1}$ & 328 & 327 \\
\hline
\end{tabular}

${ }^{a} \mathrm{P}=$ Phonetic Tape; $\mathrm{N}=$ Nonphonetic Tape. 
A significant interaction occurred between processing requirements and recording locations during the condition in which $\mathrm{CV}_{1}$ was relevant and $\mathrm{CV}_{1}$ was the evoking stimulus, $F(2,14)=5.19$, $\underline{p}<05$. This interaction is illustrated in Figure 4 . It can be seen from that figure that the latency difference between phonetic and nonphonetic processing was greatest when recorded from the left hemisphere, moderate from the vertex, and least from the right hemisphere.

No signficant latency differences were obtained for the other evoked potential components in that condition or for any of the components in other conditions of stimulus relevance.

Other measures. The procedure described by wood et al. (1971) and subsequently by Wood (1975) and by Galambos et al. (1975), was employed in the present study to test for differences in the general shape of the waveforms obtained during phonetic and nonphonetic processing of stimuli. For each hemisphere, a Wilcoxen matchedpairs signed-ranks test (Siegel, 1956) was performed on the digitized output voltages at each of 180 time points over a duration of 540 msecs. Each time point represents an interval of 3 msecs.

To reduce the probability of a Type I error, a .02 probability level was chosen for the Wilcoxen tests. Since 180 tests were performed for each pair of averages, it would be expected that approximately four of the tests for each pair would reach significance on the basis of chance. 
TASK

PHONETIC

NONPHONETIC

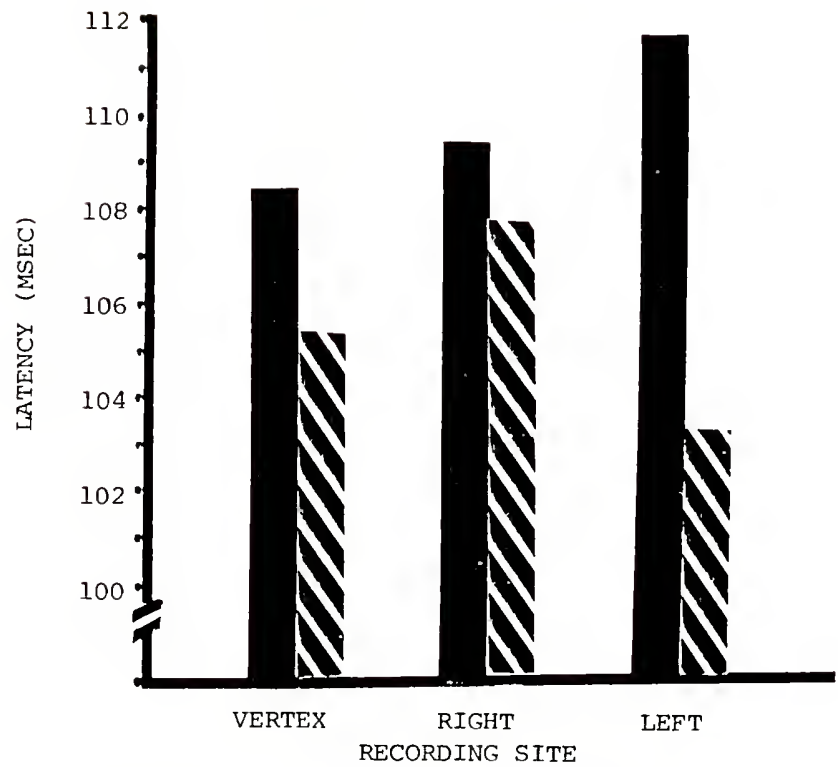

Figure 4. Latencies for $\mathrm{N}_{1}$ component of potentials evoked by $\mathrm{CV}_{1}$ during phonetic and nonphonetic processing tasks. 
The pairs of averages on which the wilcoxen tests were performed are shown in Figure 5. The upper tracings in each of the four sections of that figure are averages of potentials recorded from the left hemisphere; the lower tracings are from the right hemisphere. The solid lines are averages of potentials evoked by stimuli on the phonetic tapes; the dotted lines by stimuli on the nonphonetic tapes. Each pair of averages is anchored at the 6 msec baseline.

Figure $5 \mathrm{a}$ and $5 \mathrm{~b}$ show averages recorded during the conditions in which $\mathrm{CV}_{1}$ was the relevant stimulus. In Figure $5 \mathrm{a}$ are potentials evoked by $\mathrm{CV}_{1}$; in Figure $5 \mathrm{~b}$ are potentials evoked by $\mathrm{T}_{1}$. Figure $5 \mathrm{c}$ and 5d show corresponding averages obtained during the conditions when $T_{1}$ was the relevant stimulus.

It can be seen in Figure $5 a$ that, while the right hemisphere's responses to $\mathrm{CV}_{1}$ are virtually identical when evoked by stimuli on phonetic and nonphonetic tapes, the left hemisphere's responses to those stimuli are relatively dissimilar. The absolute difference obtained is not a large one, only about 2 microvolts. But considering that the mean peak-to-peak amplitudes are about 13 microvolts, this represents a 15 percent difference. This difference suggests that the left hemisphere's activity in response to a speech sound differs when the stimulus is processed phonetically'. There is little difference in either hemisphere's response to $\mathrm{T}_{1}$ in that condition.

Table 7 shows the number of time points at which differences between the potentials evoked by phonetic and nonphonetic tapes 


\section{EVOKING \\ STIMULUS}

$\mathrm{CV}_{1}$

a. L

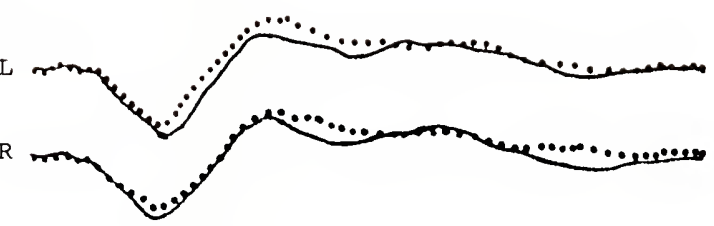

b. L

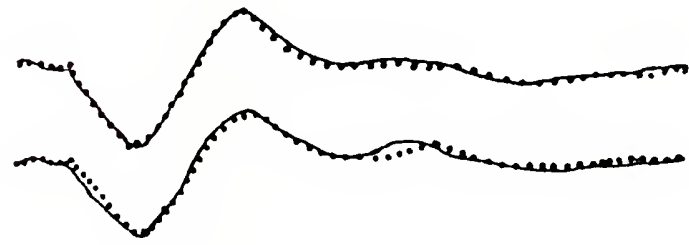

$\mathrm{CV}_{1}$

c. $\mathrm{L}$
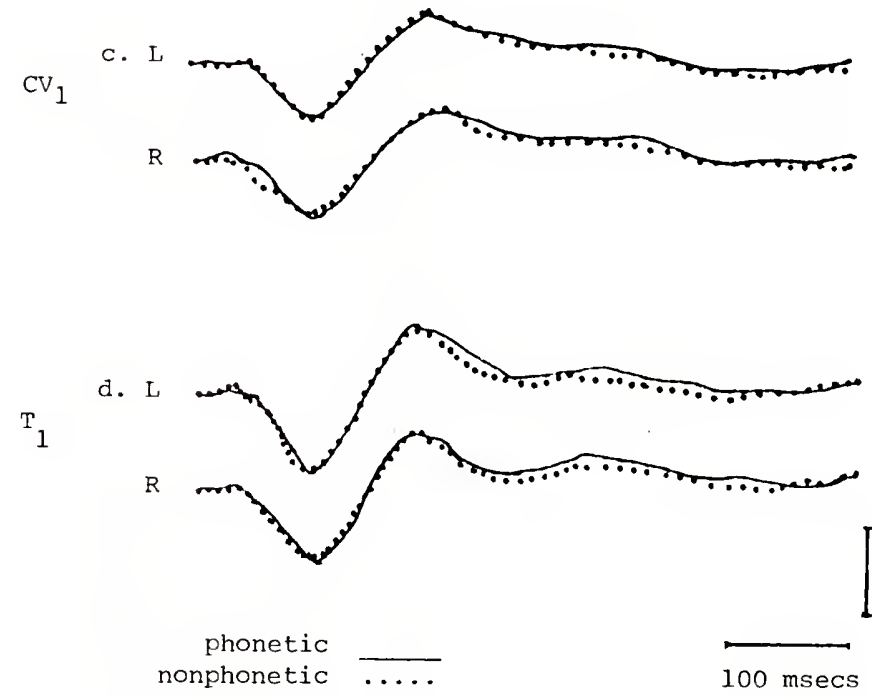

RELEVANT

STIMULUS

$\mathrm{CV}_{1}$

$\mathrm{CV}_{1}$

$T_{1}$

Figure 5. Averaged evoked potentials recorded from left and right hemispheres during phonetic and nonphonetic tasks. Calibration $=10$ microvolts . 
Table 7

Significant Wilcoxen Tests between Potentials Evoked by Stimuli on Phonetic and Nonphonetic Tapes

\begin{tabular}{|c|c|c|c|}
\hline \multirow{2}{*}{$\begin{array}{l}\text { Evoking } \\
\text { Stimulus }\end{array}$} & \multicolumn{3}{|c|}{ Hemisphere } \\
\hline & \multicolumn{2}{|c|}{ Left } & \multirow[t]{2}{*}{ Right } \\
\hline & Relevant Stimulus: & $\mathrm{CV}_{1}$ & \\
\hline $\mathrm{CV}_{1}$ & & 35 & 6 \\
\hline \multirow[t]{2}{*}{$\mathrm{T}_{1}$} & & 0 & 0 \\
\hline & Relevant Stimulus: & $\mathrm{T}_{1}$ & \\
\hline $\mathrm{CV}_{1}$ & & 0 & 1 \\
\hline $\mathrm{T}_{1}$ & & 4 & 0 \\
\hline
\end{tabular}


were found to be significant. It can be seen that the left hemisphere's response to the $\mathrm{CV}_{1}$ stimulus on the two tapes differed significantly at several points along the time continuum during the condition when $\mathrm{CV}_{1}$ was relevant. This is particularly true in the region of the $\mathrm{P}_{2}$ component--18 significant differences occurred between 170 msecs and 240 msecs following stimulus onset. Not only is 35 significant points out of 180 substantially above the chance number of four, but because the significant points tend to be clustered in certain regions of the waveform and not distributed randomly buttresses the validity of the difference.

In contrast, the number of points which were significantly different for the right hemisphere's averages in the $\mathrm{CV}_{1}$ relevant condition for the $\mathrm{CV}_{1}$ evoking stimulus is six, very close to chance expectation. There were no significantly different points for either the left or the right hemisphere responses evoked by $\mathrm{T}_{1}$. Comparable tests were computed when $\mathrm{T}_{1}$ was the relevant stimulus. The results of these tests are shown in Table 6 also. It can be seen that neither hemisphere responded differentially to the $\mathrm{CV}_{1}$ stimulus when $\mathrm{T}_{1}$ was relevant. In other words, when $\mathrm{T}_{1}$ was the stimulus to be discriminated it made no difference whether the speech stimuli on the two tapes were phonetically different or only acoustically different. Again, few differences occurred between the averages evoked by $\mathrm{T}_{1}$. Figure $5 \mathrm{c}$ and $5 \mathrm{~d}$ illustrate these findings. 


\section{Effects of Stimulus Relevance}

Amplitude measures. Amplitudes of vertex potentials were analyzed for the general effects of stimulus relevance after combining the data for phonetic and nonphonetic conditions. Amplitudes of the components are presented in Table 8 .

Significant main effects due to stimulus relevance were obtained in the analyses of the $\mathrm{N}_{1}-\mathrm{P}_{2}$ peak-to-peak amplitudes and of the $\mathrm{P}_{2}$, $\mathrm{N}_{2}$ and $\mathrm{P}_{3}$ peak amplitudes. The values are shown in Table 8 . In that table the column labelled $R / R$ shows data obtained when the evoking stimulus, either $\mathrm{CV}_{1}$ or $\mathrm{T}_{1}$, was the relevant stimulus; $\mathrm{I} / \mathrm{R}$ shows data obtained when the evoking stimulus was an irrelevant stimulus but of the same class (i.e. speech or nonspeech) as the relevant stimulus; I/I shows data when the evoking stimulus was irrelevant and of the irrelevant class.

Results of statistical tests for the various components of the potentials are summarized below.

1. $\mathrm{N}_{1}-\mathrm{P}_{2}$ components. Results of Tukey's a posteriori tests showed that the mean amplitude of the $\mathrm{N}_{1}-\mathrm{P}_{2}$ component was significantly smaller in the control conditions than in all of the conditions of stimulus relevance, $p<.01$. The three stimulus relevance conditions did not differ significantly from one another. Since no difference among conditions was obtained for $\mathrm{N}_{1}$, the differences in $\mathrm{N}_{1}-\mathrm{P}_{2}$ are due to changes in $\mathrm{P}_{2}$ in the various conditions.

2. $\mathrm{P}_{2}$ component: The $\mathrm{P}_{2}$ component of the control conditions was significantly smaller than in the other conditions, $\underline{p}<.01$, but 
Table 8

Mean Amplitudes (microvolts) of Evoked Potential Components in Conditions of Stimulus Relevance

\begin{tabular}{lccccccr}
\hline \multirow{7}{*}{$\begin{array}{c}\text { Com- } \\
\text { ponent }\end{array}$} & $\mathrm{R} / \mathrm{R}^{\mathrm{a}}$ & $\mathrm{I} / \mathrm{R}^{\mathrm{b}}$ & $\mathrm{I} / \mathrm{I}^{\mathrm{C}}$ & Control & $\mathrm{F}(3,21)$ & $\underline{\mathrm{p}}$ \\
\cline { 2 - 7 } $\mathrm{N}_{1}$ & 11.4 & 11.5 & 11.4 & 10.8 & .49 & $\mathrm{n} . \mathrm{s}$. \\
$\mathrm{P}_{2}$ & 11.6 & 10.8 & 11.1 & 7.6 & 9.10 & $<.001$ \\
$\mathrm{~N}_{1}-\mathrm{P}_{2}$ & 23.0 & 22.3 & 22.5 & 18.4 & 8.94 & $<.001$ \\
$\mathrm{~N}_{2}$ & .7 & -1.0 & -1.2 & -2.7 & 6.26 & $<.01$ \\
$\mathrm{P}_{3}$ & 4.5 & 2.7 & 2.4 & 1.1 & 9.78 & $<.001$ \\
\hline
\end{tabular}

Note: A positive amplitude for $\mathrm{N}_{2}$ means that the most negative peak between $\mathrm{P}_{2}$ and $\mathrm{P}_{3}$ was above the baseline.

a Relevant stimulus, relevant class.

bIrrelevant stimulus, relevant class.

cIrrelevant stimulus, irrelevant class. 
still no differences among the three conditions of stimulus relevance were obtained. Results of sign tests on the number of persons having larger $\mathrm{P}_{2}$ amplitudes during the stimulus relevance conditions than during the control conditions confirm the findings of the analyses of variance: all eight persons had larger $\mathrm{P}_{2}$ amplitudes in the $R / R$ and the $I / I$ conditions than in the control, $\underline{p}<.01$; seven of the eight subjects had larger $\mathrm{P}_{2}$ amplitudes in the $I / R$ condition than in the control, $\underline{p}<.05$.

3. $\mathrm{N}_{2}$ component. Although no clear $\mathrm{N}_{2}$ or $\mathrm{P}_{3}$ components were evoked during control conditions, for the sake of demonstrating the differences between the control and other conditions, values for these components were determined according to the procedure defined earlier in this section of the paper. Tukey's test showed the mean amplitude of $\mathrm{N}_{2}$ to be significantly different when evoked by a relevant stimulus than in the control condition, p $<.01 . \mathrm{N}_{2}$ potentials elicited by stimuli in the I/I condition differed from the control at the .05 level, but those in the $I / R$ condition did not reach significance at that probability level.

All eight persons had more negative $\mathrm{N}_{2}$ values in the control condition than in the $R / R$ condition ( $\underline{p}<.01$ ) and seven out of eight persons had more negative $\mathrm{N}_{2}$ values in the control than in the $I / R$ or the I/I conditions $(\underline{p}<05)$.

4. $\mathrm{P}_{3}$ component. The amplitude of the $\mathrm{P}_{3}$ component showed the greatest differential effect across the conditions of stimulus relevance. The mean amplitudes are $4.5,2.7,2.4$, and .1 for $R / R$, 
$I / R, I / I$, and control conditions, respectively. Tukey's tests showed that the mean $\mathrm{P}_{3}$ amplitude in Condition $R / R$ was significantly different from the control (p<.01); mean amplitude in Condition I/R was significantly different from the control (p<.05); but the difference between I/I amplitude and the control failed to reach significance. Differences among means of the stimulus relevance conditions failed to reach significance.

The group averages to $\mathrm{CV}_{1}$ and $\mathrm{T}_{1}$ evoking stimuli are shown in Figure 6. Because of differences in latency of $\mathrm{P}_{3}$ for different subjects, however, the group averages do not provide accurate representations of the individual subjects' responses, which are shown in Figures 7 and 8 . It can be seen from these last two figures that some subjects (e.g. Subject 2) gave relatively large $\mathrm{P}_{3}$ responses while others exhibited small, if any, $\mathrm{P}_{3}$ 's (e.g. Subject 4).

In evaluating the number of persons whose $\mathrm{P}_{3}$ amplitudes showed certain effects, it was found that all eight had larger $P_{3}$ amplitudes in Conditions $R / R$ and $I / I$ than in the control condition $(\underline{p}<01)$, and seven out of eight persons had larger $\mathrm{P}_{3}$ amplitudes in the $I / R$ condition than in the control condition (p<.05). Also, seven out of the eight persons had larger $\mathrm{P}_{3}$ amplitudes in the $R / R$ condition than in the $I / I$ condition $(\underline{p}<05)$. Six persons had larger $\mathrm{P}_{3}$ amplitudes in the $\mathrm{R} / \mathrm{R}$ condition than in the $\mathrm{I} / \mathrm{R}$ condition, but this frequency does not quite reach significance. 
Latency measures. The only significant latency difference occurred with the $\mathrm{N}_{2}$ component. It was found that the mean latency was significantly shorter during conditions when the evoking stimuli were relevant (277 msecs) than in the control condition (294 msecs), $\underline{p} \cdot 05$. The $\mathrm{N}_{2}$ latency in the $\mathrm{R} / \mathrm{R}$ condition did not differ significantly from the latency in the $I / R$ conditions or the I/I conditions, both of which were $288 \mathrm{msec}$.

In addition to all the data reported above, partial data were collected on two other subjects. These data are summarized in Appendix C. Though the data are incomplete they are consistent with the effects reported above. 


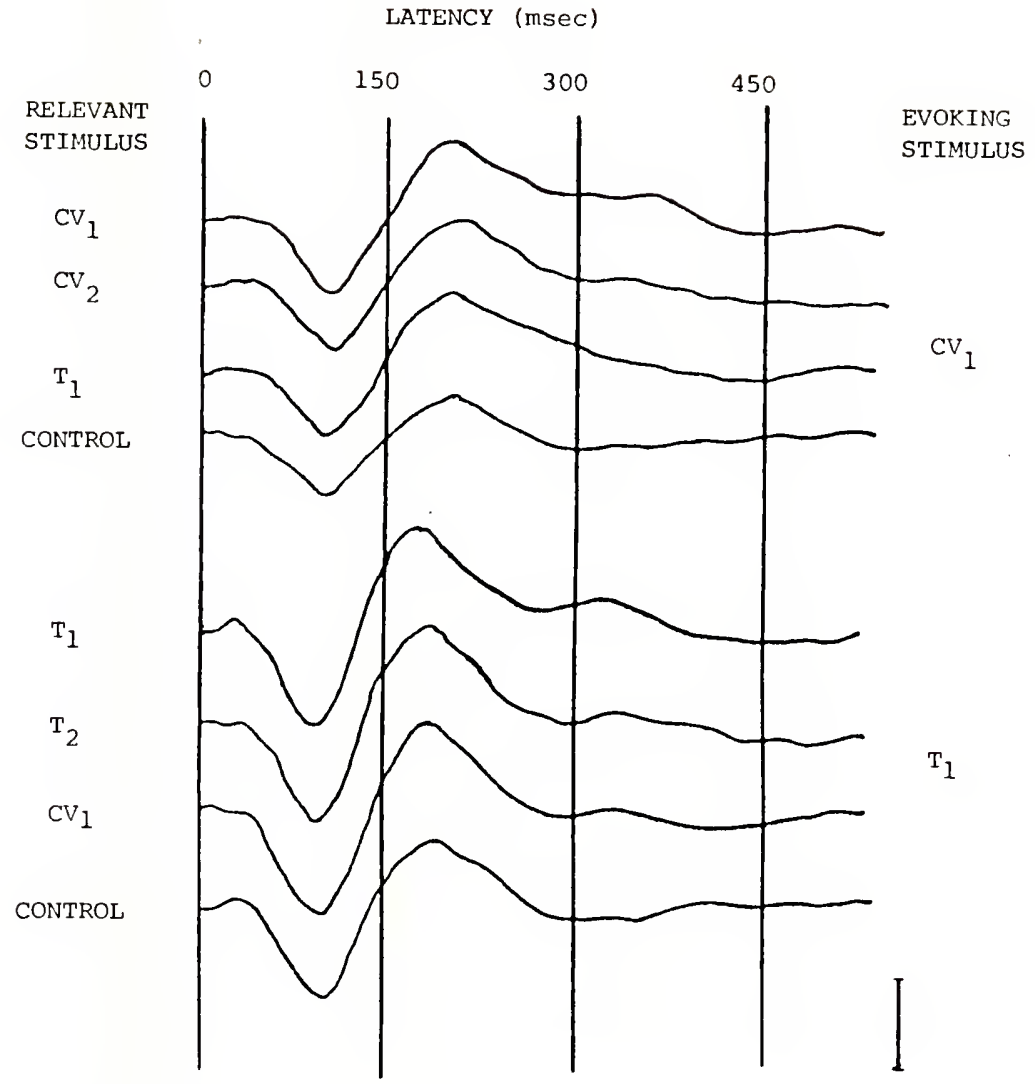

Figure 6. Averaged evoked potentials recorded from the vertex to $\mathrm{CV}_{1}$ (upper) and $\mathrm{T}_{1}$ (lower) evoking stimuli during conditions of stimulus relevance. Calibration $=10$ microvolts. 

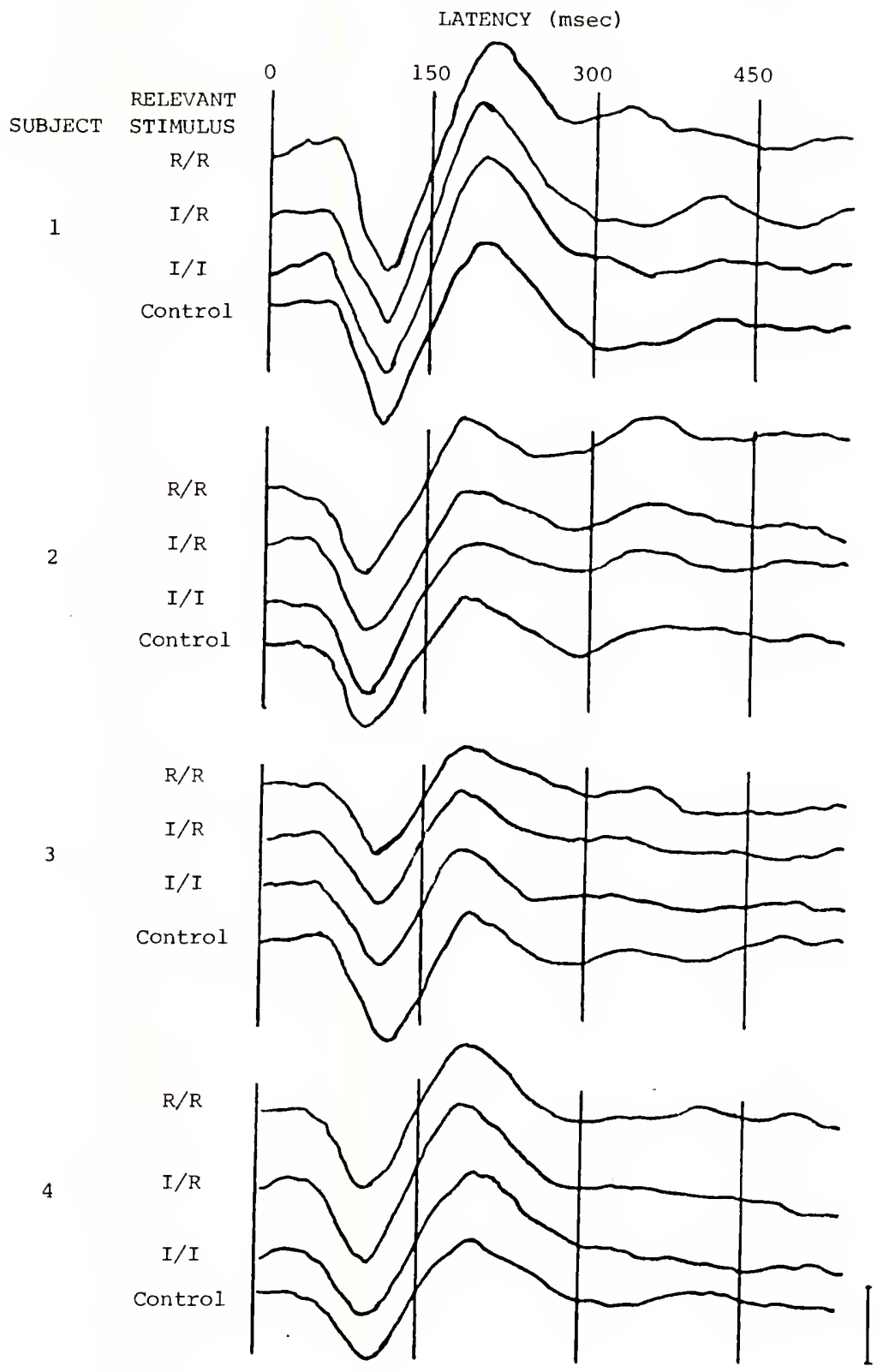

Figure 7. Averaged evoked potentials recorded from Subjects 1 - 4 during conditions of stimulus relevance. Calibration $=10$ microvolts. 

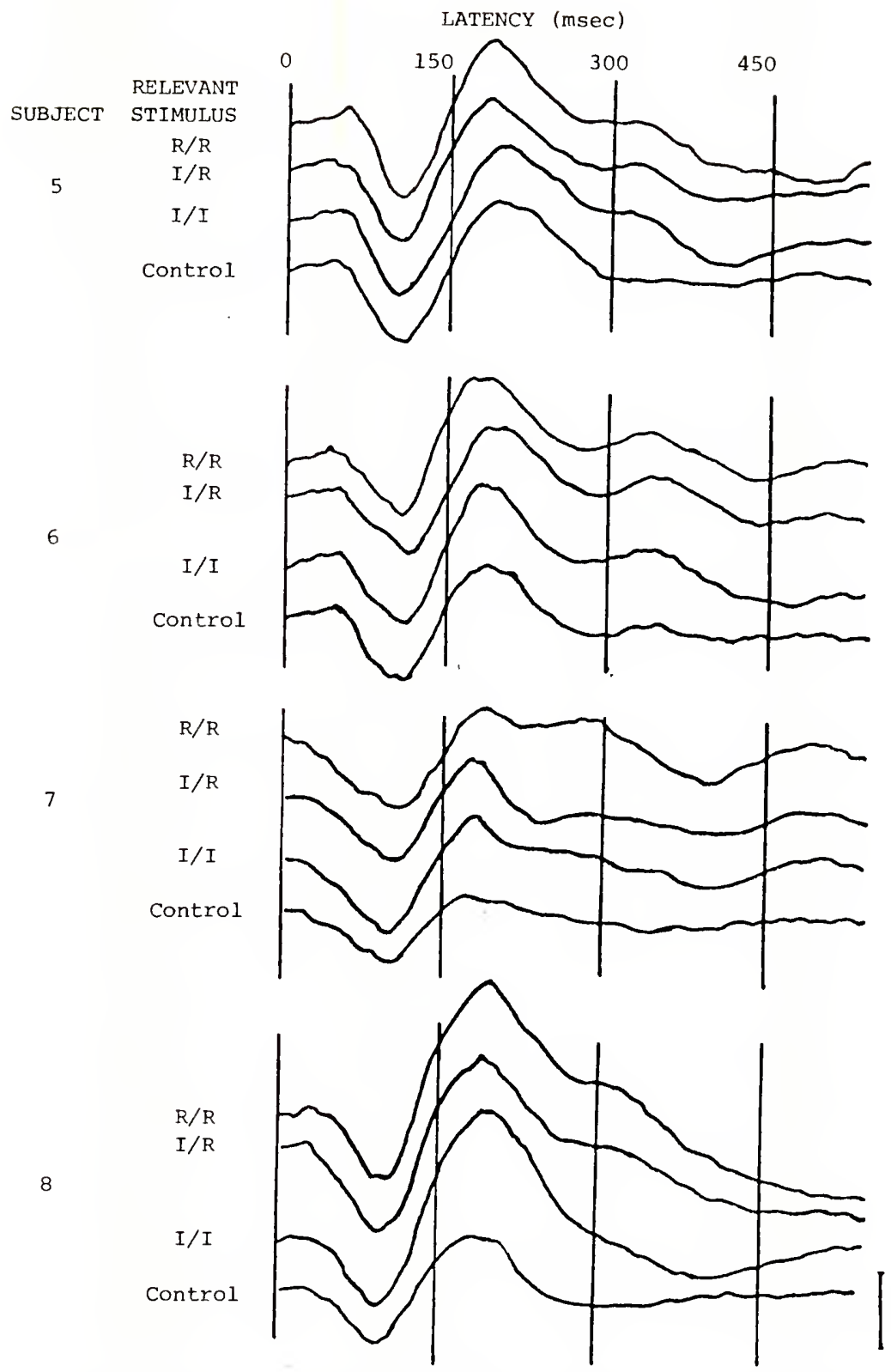

Figure 8. Averaged evoked potentials recorded from Subjects 5 - 8 during conditions of stimulus relevance. Calibration $=10$ microvolts. 


\section{DISCUSSION}

This study was designed to investigate the effects of phonetic and nonphonetic processing of stimuli on the averaged evoked potential recorded from the left and right hemispheres. A procedure was chosen to allow the following:

1. a comparison of the right hemisphere's responses with the left hemisphere's responses when the evoking stimulus was a speech signal and when it was a nonspeech signal;

2. an estimation of the relative degree of the hemispheric asymetries within subjects (i.e. R-values; voltage differences) when potentials are evoked by speech and nonspeech stimuli;

3. a comparison of the responses to stimuli presented during a phonetic processing task and a nonphonetic processing task; and

4. the investigation of a possible lateralized cortical activation in preparation for phonetic processing.

The procedures employed to effect these four objectives entailed presenting both speech and nonspeech stimuli, intermixed in a quasi-random order, to subjects engaged in a series of discrimination tasks. Given this procedure, it was desirable also to evaluate the effects of stimulus relevance and irrelevance on the components of the evoked potential. 
The data pertaining to these issues are discussed below. Topographical Effects

Hemispheric Asymmetries. The mean amplitudes of the various components of the evoked responses recorded from the left and right hemispheres did not differ significantly from each other when either the speech or the nonspeech stimulus was the evoking stimulus. In this respect, the present data agree with those reported by Galambos et al. (1975). On the other hand, the finding of no left-right differences disagrees with đata reported by Morrell and Salamy (1971) who obtained significantly larger mean $\mathrm{N}_{1}$ amplitudes from the left than from the right. It is unclear why the latter investigators' data are discrepant with those from the study by Galambos and from the present study. In the last two investigations, the experimenters reported taking extreme precautions in calibrating apparatus and controlling for extraneous factors such as balancing the use of amplifiers, etc. Morrell and Salamy did not report any such controls. Although no significant differences occurred between the two lateral recording sites, the mean amplitudes of the $\mathrm{N}_{1}$ and $\mathrm{P}_{2}$ waves recorded from the vertex were substantially larger than those of the left and right hemispheres. This finding substantiates an effect that has been reported several times previously (e.g. Vaughan \& Ritter, 1970).

Degree of Asymmetry. With respect to the R-values reported in the present investigation, there seems to be a discrepancy with the 
data reported by Molfese et al. (1975). In both studies, most subjects had R-values greater than .5 (indicating larger left hemisphere $\mathrm{N}_{1}-\mathrm{P}_{2}$ responses) when a speech signal was the evoking stimulus. However, Molfese reported smallex R-values (less than .5) to nonspeech stimuli whereas this effect was not seen in the present study. The data reported here show that most subjects had slightly larger left hemisphere responses to all stimuli, although this effect failed to reach significance.

The finding of a larger left hemisphere response to nonspeech stimuli is not unprecedented, however. The data presented by Matsumiya et al. (1972) showed that more than half their subjects had R-values greater than .5 in nonspeech conditions.

Again, the reason for the discrepancy among the results of ivestigations by Molfese, Matsumiya, and the present author are unclear. However, it is possible that it could be due to the fact that the subjects in Molfese's study listened passively throughout the experimental session while those in the other two studies were involved in tasks. If the meaningfulness of a stimulus influences hemispheric asymmetry (as Matsumiya has suggested), then it would seem that the data from the three studies do not necessarily conflict. In fact, the finding reported by Friedman et al. (1975a) that a significantly larger number of persons showed greater left hemisphere $\mathrm{N}_{1}$ responses than right hemisphere responses only when words were "signal" stimuli and not during "non-signal" or "no task" conditions supports this explanation. 
If meaningfulness does influence hemispheric asymetry, one would expect to find significantly more subjects in the present study showing larger R-values in the conditions of stimulus relevance where stimuli axe meaningful, then in the control conditions where they are not attended. The $\mathrm{N}_{1}-\mathrm{P}_{2}$ data presented in Table 2 do show such a trend: the mean number of persons (across both evoking stimuli) having larger left hemisphere responses in the $\mathrm{R} / \mathrm{R}, \mathrm{I} / \mathrm{R}, \mathrm{I} / \mathrm{I}$, and control conditions are $6.0,5.5,5.0$, and 5.0, respectively. Though the differences are small, their direction is in accord with what would be predicted if meaningfulness is a variable influencing degree of hemispheric asymetry.

To accommodate the data from previous studies as well as the present one, it is necessary to postulate that two factors, stimulus class and stimulus relevance, interact in determining the direction and degree of asymmetry. The nature of a speech stimulus may be sufficient by itself to invoke the specialized activity of the left hemisphere in a passive listening situation as demonstrated by Molfese et al. (1975), but increases in the significance or meaningfulness of a stimulus, even a nonspeech stimulus, also seems to enhance left brain activity.

Although the majority of persons in this and other studies have been found to exhibit larger left hemisphere responses to speech stimuli as compared to right hemisphere responses, it should be noted that the asymmetrical effect can be lost in the evaluation of 
group data. Since the magnitude of the asymmetry is quite small, the inclusion in an analysis of variance of data from even a couple of subjects who fail to show the effects may be sufficient to prohibit the rejection of the null hypothesis, particularly when the number of subjects in the analysis is small. Galambos et al. (1975), who also found little differences in group data, noted some substantial hemispheric asymmetries in certain individuals. Phonetic versus Nonphonetic Effects. Regarding the differences obtained during phonetic and nonphonetic processing of stimuli, there appears to be a shift toward negativity in the potential of the left hemisphere when elicited by a speech stimulus during phonetic processing. This finding confirms the data reported by Wood and his colleagues (Wood, 1975; wood et al., 1971), and extends this observation to the use of natural speech syllables. Since the two tasks differed only in their processing requirements, the differential response of the left hemisphere may reflect phonetic analysis. Because a comparable shift does not occur in the right hemisphere potential, wood (1975) proposed that the left hemisphere's potential change reflects the activity of a specialized neural center lateralized on that side. This issue is addressed in greater detail below.

Evaluation of the Lateralized Preparatory Activation Hypothesis. There is an alternative explanation for Wood's data. If, as proposed by Kinsbourne (1970), there is a preparatory arousal of the left hemisphere for processing verbal stimuli, then this might be reflected 
in the evoked potential and could account for the results of wood's studies. In the present investigation, however, the subjects had to develop a cognitive set in order to make the appropriate discriminations and responses. In the condition requiring phonetic processing of speech stimuli subjects needed to maintain a "verbal" or "linguistic" set, yet not all stimuli were speech. However, if there is a preliminary cortical arousal lateralized on the left and if this were responsible for the differential left hemisphere potential, then there should have been a differential response to the nonspeech stimulus as well as to the speech stimulus in the present study. Since this did not occur, it seems that Wood's interpretation is a valid one.

Though it can be concluded that the asymmetric activity which occurs between the two tasks cannot be explained by Kinsbourne's selective activation hypothesis, it is not possible to eliminate that theory as a viable explanation for perceptual asymetries which occur in visual half-field or dichotic listening paradigms. It simply shows that if such a functional asymmetry does exist, it is not manifest in the auditory evoked response.

In addition to the negative shift in the potential of the left hemisphere, other task differences occurred. These include a larger $\mathrm{N}_{1}$ amplitude and smaller $\mathrm{P}_{2}$ amplitude evoked by the speech stimulus in the phonetic task. Both of these differences can be accounted for by the negative shift in the waveform. 
Finally, there was a longer mean latency of the $\mathrm{N}_{1}$ component in the linguistic task which perhaps is due to a brief delay in the processing of stimuli requiring phonetic analysis.

Conclusions. Considering all existing data, two processes seem to be reflected in the auditory evoked potential to speech sounds. First, in most subjects there is a slight enhancement of the $\mathrm{N}_{1}-\mathrm{P}_{2}$ amplitude on the left and it is elicited simply by the occurance of a speech stimulus. Though there may be a corresponding asymmetry for the right hemisphere for nonspeech stimuli (Molfese et al., 1975), this asymmetry seems to be smaller or reversed when subjects are engaged in discrimination or detection tasks. Since the left hemisphere asymmetry occurs when subjects are listening passively to speech stimuli (Morrell \& Salamy, 1971; Molfese, et al., 1975) it perhaps reflects the activity of a lateralized neural center specialized for the detection of a speech signal. The activity of a second mechanism is reflected by a negativity in the evoked potential recorded from the left hemisphere which occurs during phonetic processing of a speech stimulus. This perhaps is due to a more sophisticated level of linguistic analysis rather than the simple detection of a speech stimulus.

Recently, on the basis of dichotic listening data, it has been suggested that there may be two neural mechanisms lateralized in the left hemisphere (Cutting, 1974). In a series of experiments, Cutting found that employing stimuli with frequency transitions 
results in a significantly larger right ear advantage than using stimuli without transitions. This was true for both speech (syllables) and nonspeech (frequency modulated sine waves) stimuli. It was also the case, however, that the speech stimuli gave larger right ear advantages than nonspeech stimuli for both transitioned and steady-state signals. Thus, cutting concluded that there is one left hemisphere mechanism which responds to acoustic changes (i.e. frequency transitions) which are characteristic of speech sounds, and a second mechanism which is responsible for phoneme identification. It would seem that the former mechanism, providing an acoustic analysis, would require no active linguistic processing, whereas there would be no functional reason for the latter mechanism to be activated unless speech processing does occur.

The two effects which have been seen in the evoked potential data complement the dichotic listening data quite well in their suggestion of two left hemisphere mechanisms. The $\mathrm{N}_{1}-\mathrm{P}_{2}$ amplitude asymmetry may relate to specific auditory analysis, since it seems to be related to conditions of passive listening. The negative shift, also in the region of $\mathrm{N}_{1}$ and $\mathrm{P}_{2}$, is related to phonemic analysis. Wood (1975) has demonstrated that a comparable shift does not occur during various types of acoustic processing.

Since the two asymmetrical effects occur at similar regions of the potential, it seems that both levels of processing, auditory and phonetic, are able to occur simultaneously. This, too, is consistent with current models of speech perception (e.g. Wood, 1974). . 
In conclusion, given the assumption that phonetic analysis was required when the "low / ba/" $\left(\mathrm{CV}_{1}\right)$ was relevant and had to be discriminated from the "low /da/" and from the nonspeech stimuli, and given the assumption that phonetic analysis was not required when the nonspeech stimuli were relevant or when the "low /ba/" was relevant but had to be discriminated from the "high /ba/" and the nonspeech stimuli, the data from the present study clearly support the contention that phonetic processing function of the left hemisphere is reflected in the evoked potentials recorded from the two hemispheres. The existence of the other mechanism, influencing the $\mathrm{N}_{1}-\mathrm{P}_{2}$ amplitude, was not directly supported by data in the present study, but may be responsible for preliminary acoustic analysis of incoming signals. At present the available electrophysiological data on hemispheric asymmetries are not sufficient for proposal of a definitive model of specific neural events which occur during linguistic processing. Because of this the present discussion has been restricted primarily to the findings of the present study and their relation to existing data. Hopefully such a model will be possible in the future.

Stimulus Relevance

Evoked potentials were recorded to a speech and a nonspeech stimulus during four conditions of relevancy: (a) when the evoking stimulus was the relevant stimulus; (b) when it was an irrelevant stimulus but of the same class as the relevant stimulus; (c) when it was an irrelevant stimulus of the irrelevant class; and (d) 
during the reading controls. Participation in the discrimination tasks was found to enhance the $\mathrm{N}_{1}-\mathrm{P}_{2}$ amplitude, primarily through enhancing $\mathrm{P}_{2}$. The enhancement of these components during discrimination or detection tasks is a previously established finding (Davis, 1964; Hirsch, 1971).

The only component showing a difference among the three conditions of stimulus relevance is $P_{3}$. The firiding that the amplitude of $\mathrm{N}_{2}$ was not affected by the degree of relevance is in accord with the hypothesis proposed by Ford et al. (1973) that $\mathrm{N}_{2}$ is related to stimulus modality. Since all stimuli in the present study were auditory, no difference in amplitudes is consistent with that hypothesis.

Finally, the finding that the size of $\mathrm{P}_{3}$ seems to be ordered the way they are supports a neural template model proposed by Hillyard et al. (1971). In Hillyard's study, $\mathrm{P}_{3}$ waves were elicited by "hits" in a signal detection paradigm (i.e. when a subject correctly reported the presentation of a signal in a noise background), but not by "correct rejections" (when a subject correctly reported the nonpresentation of the signal). In a later experiment, Squires, Squires and Hillyard (1975) demonstrated that a $P_{3}$ potential can be obtained to "correct rejections" under certain circumstances, but if the probability of a signal being present in a signal detection paradigm is .5 , then the $\mathrm{P}_{3}$ is larger to the "hits" than to the "correct rejections." Those authors attributed 
this to the match of sensory input (which occurs during "hit" trials) to a neural template for the signal.

In the present study, if subjects matched incoming sensory signals to a stored template of the relevant stimulus, then the best match would occur when the evoking stimulus was the relevant stimulus, followed by the case where the evoking stimulus was at least of the same class as the relevant stimulus, and finally by the situation where the evoking stimulus was irrelevant and of the irrelevant class. This is precisely the ordering of $\mathrm{P}_{3}$ amplitudes obtained in this investigation, providing further support for a template model of $\mathrm{P}_{3}$. 
APPENDIX A

Table 9

Ordering of Stimuli on Tape 1

\begin{tabular}{|c|c|c|c|c|c|c|c|}
\hline \multicolumn{2}{|c|}{$\begin{array}{l}\text { First } \\
\text { Quarter }\end{array}$} & \multicolumn{2}{|c|}{$\begin{array}{l}\text { Second } \\
\text { Quarter }\end{array}$} & \multicolumn{2}{|c|}{$\begin{array}{l}\text { Third } \\
\text { Quarter }\end{array}$} & \multicolumn{2}{|c|}{$\begin{array}{l}\text { Fourth } \\
\text { Quarter }\end{array}$} \\
\hline CVl & CVl & $\mathrm{Tl}$ & $\mathrm{CV} 2$ & CV2 & CV1 & $\mathrm{CV} 2$ & $\mathrm{CV} 2$ \\
\hline CVI & $\mathrm{Tl}$ & CVI & $\mathrm{Tl}$ & CVI & CV2 & CVI & $\mathrm{T} 2$ \\
\hline $\mathrm{T} 1$ & $\mathrm{~T} 2$ & CV2 & CV1 & $\mathrm{T} 2$ & $\mathrm{CV} 2$ & $\mathrm{TI}$ & CV1 \\
\hline $\mathrm{T} 2$ & $\mathrm{~T} 2$ & $\mathrm{CVI}$ & $\mathrm{Tl}$ & CV2 & $\mathrm{CVI}$ & CV2 & $\mathrm{Tl}$ \\
\hline $\mathrm{CV} 2$ & $\mathrm{Tl}$ & CV2 & $\mathrm{T} 2$ & CV1 & $\mathrm{Tl}$ & $\mathrm{T} 2$ & $\mathrm{CV} 2$ \\
\hline CVI & $\mathrm{CV} 2$ & $\mathrm{~T} 2$ & $\mathrm{~T} 2$ & $\mathrm{TI}$ & CV2 & $\mathrm{T} 2$ & $\mathrm{~T} 2$ \\
\hline $\mathrm{Tl}$ & $\mathrm{CV} 2$ & $\mathrm{~T} 2$ & $\mathrm{Tl}$ & CVI & $\mathrm{T} 2$ & $\mathrm{CV} 2$ & $\mathrm{CV} 2$ \\
\hline $\mathrm{T} 2$ & $\mathrm{Tl}$ & CV2 & CV1 & CV2 & $\mathrm{T} 2$ & CV1 & $\mathrm{CVI}$ \\
\hline CV2 & $\mathrm{CVI}$ & $\mathrm{T} 2$ & CVl & $\mathrm{T} 2$ & $\mathrm{CV} 2$ & $\mathrm{~T} 2$ & $\mathrm{Tl}$ \\
\hline $\mathrm{T} 2$ & CVl & CV1 & $\mathrm{CV} 2$ & CVl & $\mathrm{T} 2$ & CV1 & CVl \\
\hline $\mathrm{T} 2$ & $\mathrm{~T} 2$ & CV2 & $\mathrm{CV} 2$ & $\mathrm{Tl}$ & CVI & CV2. & $\mathrm{T} 2$ \\
\hline $\mathrm{CV} 2$ & CVI & $\mathrm{Tl}$ & $\mathrm{Tl}$ & $\mathrm{T} 2$ & $\mathrm{~T} 1$ & $\mathrm{~T} 2$ & CV2 \\
\hline CVI & $\mathrm{Tl}$ & CVl & $\mathrm{T} 2$ & $\mathrm{~T} 1$ & $\mathrm{Tl}$ & $\mathrm{Tl}$ & $\mathrm{Tl}$ \\
\hline $\mathrm{T} 2$ & CV2 & $\mathrm{Tl}$ & $\mathrm{T} 2$ & CV2 & CV1 & $\mathrm{T} 1$ & $\mathrm{~T} 2$ \\
\hline $\mathrm{Tl}$ & $\mathrm{CV} 2$ & $\mathrm{~T} 2$ & CVl & $\mathrm{T} 1$ & $\mathrm{~T} 2$ & CV1 & $\mathrm{CVl}$ \\
\hline $\mathrm{Tl}$ & $\mathrm{T} 2$ & $\mathrm{Tl}$ & CV2 & $\mathrm{T} 2$ & $\mathrm{~T} 1$ & $\mathrm{Tl}$ & $\mathrm{Tl}$ \\
\hline CV2 & $\mathrm{T} 2$ & $\mathrm{~T} 2$ & CVI & CVI & CVl & $\mathrm{Tl}$ & $\mathrm{T} 2$ \\
\hline $\mathrm{CV} 2$ & $\mathrm{CV} 2$ & CV2 & $\mathrm{Tl}$ & CVI & $\mathrm{C} v 2$ & $\mathrm{CV} 2$ & $\mathrm{Tl}$ \\
\hline $\mathrm{T} 2$ & $\mathrm{Tl}$ & CV2 & $\mathrm{T} 2$ & CV2 & $\mathrm{Tl}$ & $\mathrm{Tl}$ & CV2 \\
\hline T1 & $\mathrm{T} 2$ & CVl & $\mathrm{T} 2$ & $\mathrm{~T} 2$ & $\mathrm{~T} 2$ & $\mathrm{~T} 2$ & $\mathrm{~T} 2$ \\
\hline $\mathrm{T} 2$ & CVI & $\mathrm{Tl}$ & $\mathrm{CV} 2$ & $\mathrm{Tl}$ & $\mathrm{T} 2$ & CVI & $\mathrm{Tl}$ \\
\hline Tl & $\mathrm{CV} 2$ & CV2 & CVI & $\mathrm{Tl}$ & $\mathrm{T} 1$ & $\mathrm{~T} 2$ & $\mathrm{CV} 2$ \\
\hline CV1 & CV1 & $\mathrm{T} 2$ & $\mathrm{Tl}$ & $\mathrm{T} 2$ & CVI & $\mathrm{Tl}$ & $\mathrm{T} 1$ \\
\hline $\mathrm{Tl}$ & CVl & $\mathrm{TI}$ & $\mathrm{T} 2$ & CVI & CV2 & CV2 & $\mathrm{CVI}$ \\
\hline CV2 & $\mathrm{Tl}$ & $\mathrm{Tl}$ & CV2 & $\mathrm{Tl}$ & $\mathrm{Tl}$ & CV2 & CVI \\
\hline CV1 & $\mathrm{CV} 2$ & $\mathrm{~T} 2$ & CVI & $\mathrm{T} 2$ & $\mathrm{CV} 2$ & CVl & $\mathrm{T} 2$ \\
\hline $\mathrm{T} 2$ & $\mathrm{TI}$ & CVI & $\mathrm{Tl}$ & CVI & CVl & $\mathrm{T} 1$ & $\mathrm{~T} 2$ \\
\hline CVI & CV2 & CV2 & $\mathrm{CV} 2$ & $\mathrm{CV} 2$ & $\mathrm{~T} 2$ & $\mathrm{~T} 2$ & CVI \\
\hline $\mathrm{CV} 2$ & $\mathrm{~T} 2$ & $\mathrm{Tl}$ & $\mathrm{T} 1$ & $\mathrm{~T} 1$ & CV2 & CV2 & CV2 \\
\hline $\mathrm{Tl}$ & $\mathrm{Tl}$ & CVl & CVI & $\mathrm{T} 2$ & CVI & CV1 & $\mathrm{TI}$ \\
\hline CVI & $\mathrm{T} 2$ & $\mathrm{~T} 2$ & CV2 & CV2 & $\mathrm{Tl}$ & $\mathrm{CVl}$ & $\mathrm{CV} 2$ \\
\hline CV2 & CVI & $\mathrm{CVl}$ & $\mathrm{T} 2$ & $\mathrm{CV} 2$ & $\mathrm{~T} 2$ & $\mathrm{~T} 2$ & $\mathrm{CVI}$ \\
\hline
\end{tabular}

Note: A phonetic and a nonphonetic tape was made with the above ordering of stimuli. 
Table 10

Ordering of Stimuli on Tape 2

\begin{tabular}{|c|c|c|c|c|c|c|c|}
\hline \multicolumn{2}{|c|}{$\begin{array}{l}\text { First } \\
\text { Quarter }\end{array}$} & \multicolumn{2}{|c|}{$\begin{array}{l}\text { Second } \\
\text { Quarter }\end{array}$} & \multicolumn{2}{|c|}{$\begin{array}{l}\text { Third } \\
\text { Quarter }\end{array}$} & \multicolumn{2}{|c|}{$\begin{array}{l}\text { Fourth } \\
\text { Quarter }\end{array}$} \\
\hline $\mathrm{Tl}$ & CVI & $\mathrm{T} 2$ & $\mathrm{~T} 2$ & CV2 & $\mathrm{CV} 2$ & $\mathrm{Tl}$ & CVI \\
\hline CV2 & $\mathrm{T} 1$ & $\mathrm{Tl}$ & CV1 & $\mathrm{Tl}$ & CV1 & CVI & CV2 \\
\hline $\mathrm{T} 2$ & CV2 & CV2 & $\mathrm{Tl}$ & $\mathrm{T} 2$ & $\mathrm{Tl}$ & $\mathrm{T} 2$ & $\mathrm{CVl}$ \\
\hline CVl & $\mathrm{T} 2$ & $\mathrm{~T} 2$ & $\mathrm{~T} 2$ & $\mathrm{~T} 1$ & $\mathrm{Tl}$ & CV2 & $\mathrm{T} 2$ \\
\hline $\mathrm{Tl}$ & $\mathrm{Tl}$ & CVI & CV2 & $\mathrm{T} 2$ & $\mathrm{~T} 2$ & CV2 & $\mathrm{Tl}$ \\
\hline $\mathrm{T} 2$ & $\mathrm{TI}$ & CVl & CV2 & CVI & CVI & CVI & $\mathrm{T} 2$ \\
\hline т2 & $\mathrm{T} 2$ & CV2 & $\mathrm{T} 2$ & CV2 & $\mathrm{Tl}$ & CV2 & $\mathrm{CVl}$ \\
\hline CV2 & CV2 & $\mathrm{Tl}$ & CV1 & CV2 & $\mathrm{T} 2$ & $\mathrm{Tl}$ & CV1 \\
\hline CV1 & $\mathrm{Tl}$ & $\mathrm{T} 2$ & CV 2 & $\mathrm{Tl}$ & CV1 & $\mathrm{T} 2$ & $\mathrm{TI}$ \\
\hline CV2 & $\mathrm{T} 2$ & CVl & CVl & $\mathrm{Tl}$ & $\mathrm{CV} 2$ & CVl & CVI \\
\hline $\mathrm{T} 2$ & CVI & $\mathrm{T} 2$ & $\mathrm{~T} 2$ & CV2 & $\mathrm{T} 2$ & $\mathrm{CV} 2$ & $\mathrm{Tl}$ \\
\hline CVl & $\mathrm{TI}$ & CVl & $\mathrm{CV} 2$ & $\mathrm{~T} 2$ & $\mathrm{~T} 2$ & $\mathrm{Tl}$ & $\mathrm{T} 2$ \\
\hline $\mathrm{Tl}$ & $\mathrm{T} 2$ & $\mathrm{CV} 2$ & $\mathrm{Tl}$ & CV2 & $\mathrm{CV} 2$ & $\mathrm{~T} 2$ & $\mathrm{~T} 2$ \\
\hline CV2 & CV2 & $\mathrm{T} 1$ & CV1 & CVI & $\mathrm{Tl}$ & CV2 & CV1 \\
\hline $\mathrm{T} 2$ & $\mathrm{~T} 2$ & CV2 & $\mathrm{TI}$ & CVl & CVI & $\mathrm{T} 2$ & $\mathrm{CV} 2$ \\
\hline $\mathrm{T} 1$ & CVI & CVl & $\mathrm{T} 2$ & $\mathrm{~T} 2$ & $\mathrm{~T} 2$ & CVl & $\mathrm{T} 1$ \\
\hline $\mathrm{CVl}$ & $\mathrm{Tl}$ & $\mathrm{T} 2$ & $\mathrm{CV} 2$ & CV1 & $\mathrm{CV} 2$ & $\mathrm{TI}$ & CVl \\
\hline $\mathrm{Tl}$ & CVl & $\mathrm{T} 2$ & $\mathrm{Tl}$ & $\mathrm{T} 2$ & $\mathrm{~T} 1$ & $\mathrm{~T} 1$ & $\mathrm{CV} 2$ \\
\hline CV 2 & CV2 & $\mathrm{CV} 2$ & $\mathrm{CV} 2$ & CV2 & $\mathrm{Tl}$ & CVI & $\mathrm{T} 2$ \\
\hline $\mathrm{T} 2$ & $\mathrm{CV} 2$ & $\mathrm{~T} 1$ & $\mathrm{Tl}$ & $\mathrm{T} 2$ & CVI & CV2 & CV2 \\
\hline CV2 & CVI & CV1 & $\mathrm{Tl}$ & T2 & CV2 & $\mathrm{T} 2$ & CVI \\
\hline CV2 & $\mathrm{T} 2$ & CVl & CV2 & $\mathrm{Tl}$ & $\mathrm{Tl}$ & $\mathrm{Tl}$ & $\mathrm{Tl}$ \\
\hline $\mathrm{Tl}$ & CV2 & $\mathrm{Tl}$ & $\mathrm{CVI}$ & CVI & $\mathrm{T} 2$ & $\mathrm{Tl}$ & $\mathrm{Tl}$ \\
\hline CVI & CVl & $\mathrm{T} 2$ & $\mathrm{~T} 2$ & CVl & $\mathrm{CV} 2$ & CV2 & $\mathrm{CV} 2$ \\
\hline CVI & $\mathrm{T} 1$ & $\mathrm{TI}$ & CV1 & $\mathrm{CV} 2$ & $\mathrm{~T} 2$ & $\mathrm{~T} 2$ & $\mathrm{~T} 2$ \\
\hline $\mathrm{Tl}$ & $\mathrm{T} 2$ & CV1 & $\mathrm{CV} 2$ & $\mathrm{CVl}$ & CV2 & $\mathrm{T} 1$ & $\mathrm{~T} 2$ \\
\hline $\mathrm{T} 2$ & CVI & $\mathrm{CV} 2$ & CV1 & $\mathrm{T} 2$ & $\mathrm{Tl}$ & $\mathrm{T} 2$ & CV1 \\
\hline $\mathrm{Tl}$ & $\mathrm{T} 2$ & $\mathrm{~T} 2$ & $\mathrm{Tl}$ & CVl & $\mathrm{CV} 2$ & $\mathrm{~T} 2$ & $\mathrm{~T} 1$ \\
\hline CV2 & CVI & $\mathrm{Tl}$ & $\mathrm{T} 2$ & CV2 & $\mathrm{Tl}$ & CVl & CVI \\
\hline CVl & $\mathrm{CV} 2$ & CVl & $\mathrm{Tl}$ & CVI & $\mathrm{Tl}$ & CV2 & $\mathrm{CV} 2$ \\
\hline CV2 & $\mathrm{Tl}$ & CV2 & $\mathrm{CV} 2$ & $\mathrm{CVI}$ & CVI & $\mathrm{CV} 2$ & $\mathrm{CV} 2$ \\
\hline $\mathrm{T} 2$ & CVl & $\mathrm{T} 2$ & $\mathrm{Tl}$ & $\mathrm{Tl}$ & $\mathrm{T} 2$ & $\mathrm{Tl}$ & $\mathrm{T} 2$ \\
\hline
\end{tabular}


APPENDIX B

Table 11

Order of Experimental Conditions

Subject Session

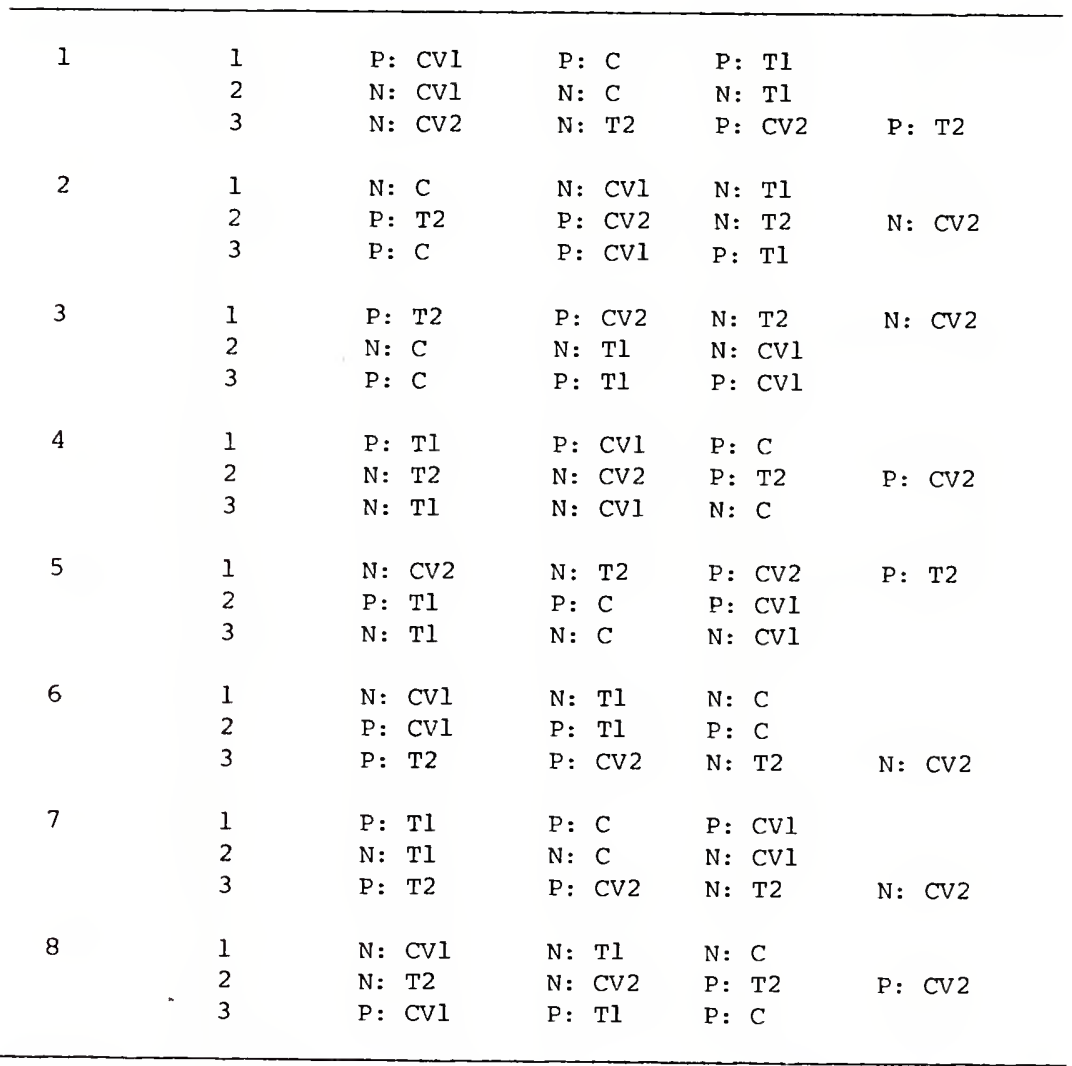

Note: Dependent variables in all conditions were amplitude and latency measures for $\mathrm{N}_{1}, \mathrm{P}_{2}, \mathrm{~N}_{2}$ and $\mathrm{P}_{3}$ components of the evoked potential recorded from vertex, left temporo-parietal, and right temporo-parietal sites. In every condition the subject was presented with a series of 256 stimuli $\left(64\right.$ each of $\mathrm{CV}_{1}, \mathrm{CV}_{2}, \mathrm{~T}_{1}$, and $\mathrm{T}_{2}$ ) and potentials were recorded to $\mathrm{CV}_{1}$ and $\mathrm{T}_{1} \cdot \mathrm{P}=$ Phonetic tape; $\mathrm{N}=$ Nonphonetic tape. 
Appendix C

Table 12

Summary of Partial Amplitude Data

(Microvolts) for two Additional Subjects

Component

Relevant Evoking Recording

\begin{tabular}{llllllllll} 
Subject & Stimulus $^{a}$ & Stimulus & Site $^{b}$ & $N_{1}$ & $P_{2}$ & $N_{1}-P_{2}$ & $N_{2}$ & $P_{3}$ \\
\hline
\end{tabular}

1

\begin{tabular}{|c|c|c|c|c|c|c|c|}
\hline $\mathrm{P}: \mathrm{CV}_{1}$ & $\mathrm{CV}_{1}$ & V & 8.9 & 7.3 & 16.2 & 2.3 & 2.9 \\
\hline & & L & 8.4 & 7.1 & 15.5 & 3.4 & 3.8 \\
\hline & & $\mathrm{R}$ & 8.8 & 5.2 & 14.0 & 1.0 & 1.3 \\
\hline & $\mathrm{T}_{1}$ & V & 12.3 & 6.2 & 18.5 & -1.9 & 1.9 \\
\hline & & L & 9.0 & 6.6 & 15.6 & .6 & 1.8 \\
\hline & & $\mathrm{R}$ & 11.0 & 5.9 & 16.9 & -1.4 & 1.5 \\
\hline $\mathrm{P}: \mathrm{T}_{1}$ & $\mathrm{CV}_{1}$ & V & 7.9 & 12.6 & 20.5 & 1.5 & 2.1 \\
\hline & & L & 9.1 & 8.8 & 17.9 & 2.4 & 3.8 \\
\hline & & $\mathrm{R}$ & 9.7 & 7.7 & 17.4 & .1 & 1.5 \\
\hline & $\mathrm{T}_{1}$ & V & 13.5 & 10.8 & 24.3 & 4.0 & 4.1 \\
\hline & & L & 10.1 & 8.7 & 18.8 & 4.9 & 5. \\
\hline & & $\mathrm{R}$ & 12.5 & 6.1 & 16.6 & 5.0 & 6.4 \\
\hline P:Control & $\mathrm{CV}_{1}$ & $\mathrm{~V}$ & 8.8 & 1.8 & 10.6 & & \\
\hline & & L & 8.3 & 1.1 & 9.4 & & \\
\hline & & $\mathrm{R}$ & 7.5 & 1.1 & 8.6 & & \\
\hline & $\mathrm{T}_{1}$ & V & 9.2 & 4.5 & 13.7 & & \\
\hline & . & L & 8.5 & 4.2 & 12.7 & & \\
\hline & & $\mathrm{R}$ & 7.9 & 3.0 & 10.9 & & \\
\hline
\end{tabular}


Table 12 (continued)

Component

\begin{tabular}{|c|c|c|c|c|c|c|c|c|}
\hline Subject & $\begin{array}{l}\text { Relevant } \\
\text { Stimulus }\end{array}$ & $\begin{array}{l}\text { Evoking } \\
\text { Stimulus }\end{array}$ & $\begin{array}{c}\text { Recording } \\
\text { Site }\end{array}$ & $\mathrm{N}_{1}$ & $\mathrm{P}_{2}$ & $\mathrm{~N}_{1}-\mathrm{P}_{2}$ & $\mathrm{~N}_{2}$ & $\mathrm{P}_{3}$ \\
\hline \multirow[t]{9}{*}{2} & $\mathrm{P}: \mathrm{CV}_{1}$ & $\mathrm{CV}_{1}$ & v & 7.1 & 4.0 & 11.1 & -1.6 & 2.6 \\
\hline & & & $\mathrm{L}$ & 5.9 & 3.3 & 9.2 & .1 & 3.6 \\
\hline & & & $\mathrm{R}$ & 5.5 & 1.6 & 7.1 & 1.0 & 4.5 \\
\hline & $\mathrm{P}: \mathrm{T}_{1}$ & $\mathrm{CV}_{1}$ & $\mathrm{v}$ & 3.7 & 5.6 & 9.3 & -2.6 & 2.2 \\
\hline & & & $\mathrm{L}$ & 3.3 & 2.7 & 6.0 & -1.3 & 3.0 \\
\hline & & & $\mathrm{R}$ & 2.9 & .8 & 3.7 & -.3 & 1.5 \\
\hline & P:Control & $\mathrm{CV}_{1}$ & $\mathrm{v}$ & 7.0 & 1.1 & 8.1 & & \\
\hline & & & L & 9.3 & .1 & 9.4 & & \\
\hline & & & $\mathrm{R}$ & 8.4 & .2 & 8.6 & & \\
\hline
\end{tabular}

$\mathrm{a}_{\mathrm{P}}=$ Phonetic tapes; $\mathrm{N}=$ Nonphonetic Tapes

$\mathrm{b}_{\mathrm{V}}=$ Vertex $\mathrm{L}=$ Left Temporo-Parietal; $\mathrm{R}=$ Right Temporo-Parietal. 


\section{REFERENCES}

Benson, D. A., \& Teas, D. C. Single unit study of binaural interaction in the auditory cortex of the chinchilla. Brain Research, 1976, 103, 313-338.

Bogen, J. E., \& Gordon, H. W. Musical tests for functional lateralization with intracarotid amobarbital. Nature, 1971, $230,524-525$.

Branch, C., Milner, B., \& Rasmussen, T. Intracarotid sodium amytal for the lateralization of cerebral speech dominance. Journal of Neurosurgery, 1964, 21, 399-405.

Broadbent, D. E. The role of auditory localization in attention and memory span. Journal of Experimental Psychology, 1954, 47, 191-196.

Broadbent, D. E., \& Gregory, M. Accuracy of recognition for speech presented to the right and left ears. Quarterly Journal of Experimenta1 Psychology, 1964, 16, 359-360.

Bryden, M. P. Tachistoscopic recognition of non-alphabetical material. Canadian Journal of Psychology, 1960, 14, 78-86.

Bryden, M. P. Tachistoscopic recognition, handedness, and cerebral dominance. Neuropsychologia, 1965, 3, 1-8.

Bryden, M. P. Left-right differences in tachistoscopic recognition: directional scanning or cerebral dominance? Perceptual and Motor Skills, 1966, 23, 1127-1134.

Bryden, M. P., \& Rainey, C. A. Left-right differences in tachistoscopic recognition. Journal of Experimental Psychology, 1963, 66, 568-571.

Butler, R. A., Keidel, W. D., \& Spreng, M. An investigation of the human cortical evoked potential under conditions of monaural and binaural stimulation. Acta Otolaryngologica, $1969,68,317-326$. 
Cohen, G. Hemispheric differences in a letter classification task. Perception and Psychophysics, 1972, 11, 139-142.

Cohn, R. Differential cerebral processing of noise and verbal stimuli. Science, 1971, 172, 599-601.

Curry, F. K. A comparison of left-handed and right-handed subjects on verbal and non-verbal dichotic listening tasks. Cortex, $1967,3,343-352$.

Curry, F. K., \& Rutherford, D. R. Recognition and recall of dichotically presented verbal stimuli by right- and lefthanded persons. Neuropsychologia, 1967, 5, 119-126.

Cutting, J. E. Two left-hemisphere mechanisms in speech perception. Perception and Psychophysics, 1974, 16, 601-612.

Davis, H. Enhancement of evoked cortical potentials in humans related to a task requiring a decision. Science, 1964, 145, 182-183.

Davis, H., Mast, T., Yoshie, N., \& Zerlin, S. The slow response of the human cortex to auditory stimuli: recovery process. Electroencephalography and Clinical Neurophysiology, 1966, 21, 601-612.

Davis, H., \& Zerlin, S. Acoustic relations of the human vertex potential. Journal of the Acoustical Society of America, $1966,39,109-116$.

Debecker, J., \& Desmedt, J. E. Rate of intermodality switching disclosed by sensory evoked potentials averaged during signal detection tasks. Journal of Physiology, 1966, 185, 52P-53P.

Dirks, D. Perception of dichotic and monaural verbal material and cerebral dominance for speech. Acta Otolaryngologica, $1964,86,403-425$.

Donchin, E., \& Cohen, L. Averaged evoked potentials and intramodality selective attention. Electroencephalography and Clinical Neurophysiology, 1967, 22, 537-546.

Ellis, H. D., \& Shepherd, J. W. Recognition of upright and inverted faces presented in the left and right visual fields. Cortex, 1975, 11, 3-7.

Ford, J. M., Roth, W. T., Dirks, S. J., \& Kopell, B. S. Evoked potential correlates of signal recognition between and within modalities. Science, 1973, 181, 465-466. 
Friedman, D., Simson, R., Ritter, W., \& Rapin, I. Cortical evoked potentials elicited by real speech words and human sounds. Electroencephalography and Clinical Neurophysiology, $1975 \mathrm{a}, 38,13-19$.

Friedman, D., Simson, R., Ritter, W., \& Rapin, I. The late positive component ( $\mathrm{P} 300)$ and the information processing in sentences. Electroencephalography and Clinical Neurophysiology, $1975 b, 38,255-262$.

Galambos, R., Benson, P., Smith, T. S., Schulman-Galambos, C., \& osier, H. On hemispheric differences in evoked potentials to speech stimuli. Electroencephalography and Clinical Neurophysiology, 1975, 39, 279-283.

Galin, D., \& Ellis, R. R. Asymmetry in evoked potentials as an index of lateralized cognitive processes: relation to EEG alpha asymmetry. Neuropsychologia, 1975, 13, 45-50.

Galin, D., \& Ornstein, R. Lateral specialization of cognitive mode: an EEG study. Psychophysiology, 1972, 9, 412-418.

Gazzaniga, M. S., \& Hillyard, S. A. Language and speech capacity of the right hemisphere. Neuropsychologia, 1971, 9, 273-280.

Gazzaniga, M. S., \& Sperry, R. W. Language after section of the cerebral commissures. Brain, 1967, 90, 131-148.

Geffen, G., Bradshaw, J. L., \& Nettleson, N. C. Hemispheric asymmetry: verbal and spatial encoding of visual stimuli. Journal of Experimental Psychology, 1972, 95, 25-31.

Geffen, G., Bradshaw, J. L., \& Wallace, G. Interhemispheric effects on reaction time to verbal and nonverbal visual stimuli. Journal of Experimental Psychology, 1971, 87, 415-422.

Geschwind, N., \& Levitsky, W. Human brain: left-right asymmetries in temporal speech region. Science, 1968, 161, 186-187.

Gordon, H. W., \& Bogen, J. E. Hemispheric lateralization of singing after intercarotid sodium amylobarbitone. Journal of Neurology, Neurosurgery, and Psychiatry, 1974, 37, 727-738.

Gross, M. M., Begleiter, H., Tobin, M., \& Kissin, B. Auditory evoked response comparison during counting clicks and reading. Electroencephalography and Clinical Neurophysiology, 1965, 18, 451-454. 
Hall, J. L., \& Goldstein, M. H. Representation of binaural stimuli by single units in primary auditory cortex of unanesthetized cats. The Journal of the Acoustical Society of America, 1968, 43,456-461.

Heilbrun, A. B., Jr. Psychological test performance as a function of lateral localization of cerebral lesion. Journal of Comparative and Physiological Psychology, $195 \overline{6,49,10-14}$.

Heron, W. Perception as a function of retinal locus and attention. American Journal of Psychology, 1957, 70, 38-48.

Hillyard, S. A., Squires, K. C., Bauer, J. W., \& Lindsay, P. H. Evoked potential correlates of auditory signal detection. Science, 1971, 172, 1357-1360.

Hines, D., \& Satz, P. Superiority of right visual half-fields in right-handers for recall of digits presented at varying rates. Neuropsychologia, 1971, $9,21-25$.

Hirsh, S. K. Vertex potentials associated with an auditory discrimination. Psychonomic Science, 1971, 22, 173-175.

Kaufer, I., Morais, J., \& Bertelson, p. Lateral differences in tachistoscopic recognition of bilaterally presented verbal material. Acta Psychologica, 1975, 39, 369-376.

Kimura, D. Some effects of temporal-lobe damage on auditory perception. Canadian Journal of Psychology, 1961, 15, 156-165.

Kimura, D. Dual functional asymmetry of the brain in visual perception. Neuropsychologia, 1966, 4, 275-285.

Kimura, D. Functional asymmetry of the brain in dichotic listening. Cortex, 1967, 3, 163-178.

Kimura, D., \& Folb, S. Neural processing of backwards speech sounds. Science, 1968, 161, 395-396.

Kinsbourne, M. The cerebral basis of lateral asymmetries in attention. Acta Psychologica, 1970, 33, 193-201.

Kirk, R. E. Experimental Design: Procedures for the Behavioral Sciences. Belmont, California: Brooks/Cole Publishing Company, 1968.

Klove, H. Relationship of differential electroencephalographic patterns to distribution of Wechsler- Bellevue scores. Neurology, 1959, 9 , 871-876. 
LeMay, M., \& Culebras, A. Human brain -- morphologic differences in the hemispheres demonstrable by carotid arteriography. New England Journal of Medicine, 1972, 287, 168-170.

Levy, J., Nebes, R. D., \& Sperry, R. W. Expressive language in the surgically separated minor hemisphere. Cortex, 1971, 7. $49-58$.

Mast, T. E., \& Watson, C. S. Attention and auditory evoked responses to low-detectability signals. Perception and Psychophysics, 1968, 4, 237-240.

Matsumiya, Y., Tagliasco, V., Lombroso, C. T., \& Goodglass, H. Auditory evoked response: meaningfulness of stimuli and interhemispheric asymmetry. Science, 1972, 175, 790-793.

McFie, J., \& Piercy, M. F. Intellectual impairment with localized cerebral lesions. Brain, 1952, 75, 292-311.

McKee, G., Humphrey, B., \& McAdam, D. W. Scaled Iateralization of alpha activity during linguistic and musical tasks. Psychophysiology, 1973, 10, 441-443.

McKeever, W. F., \& Huling, M. D. Lateral dominance in tachistoscopic word recognition performances obtained with simultaneous bilateral input. Neuropsychologia, 1971, 9, 15-20.

Meyer, V., \& Yates, A. J. Intellectual changes following temporal lobectomy for psychomotor epilepsy. Journal of Neurology, Neurosurgery, and Psychiatry, 1955, 18, 44-52.

Milner, B. Psychological defects produced by temporal lobe excision. Research Publications of the Association of Nervous and Mental Disorders, 1958, 36, 244-257.

Mishkin, M., \& Forgays, D. G. Word recognition as a function of retinal locus. Journal of Experimental Psychology, 1952, $\underline{43}, 43-48$.

Molfese, D. L., Freeman, R. B., Jr., \& Palermo, D. S. The ontogeny of brain lateralization for speech and nonspeech stimuli. Brain and Language, 1975, 2, 356-368.

Morgan, A. H., MacDonald, H., \& Hilgard, E. R. EEG alpha: lateral asymmetry related to task, and hypnotizability. Psychophysiology, 1974, 11, 275-282.

Morgan, A. H., McDonald, P. J., \& MacDonald, H. Differences in bilateral alpha activity as a function of experimental task, with a note on lateral eye movements and hypnotizability. Neuropsychologia, 1971, 9 , 459-469. 
Morre11, L. K., \& Salamy, J. G. Hemispheric asymmetry of electrocortical responses to speech stimuli. Science, $1971,174,164-166$.

Naatanen, R. Selective attention and evoked potentials in humans--a critical review. Biological Psychology, 1975, 2, 237-307.

Onishi, S., \& Davis, H. Effects of duration and rise time of tone bursts on evoked $\mathrm{V}$ potentials. Journal of the Acoustical Society of America, 1968, $\underline{44}, 582-591$.

Penfield, W., \& Roberts, L. Speech and Brain Mechanisms. Princeton: Princeton University Press, 1959.

Perria, L., Rosadini, G., \& Rossi, G. F. Determination of side of cerebral dominance with amobarbital. Archives of Neurology, 1961, 4, 173-181.

Picton, T. W., Hillyard, S. A., Krausz, H. I., \& Galambos, R. Human auditory evoked potentials. I: Evaluation of components. Electroencephalography and Clinical Neurophysiology, 1974, 36, 179-190.

Rapin, I., Schimmel, H., Tourk, L. M., Krasnegor, N. A., \& Pollack, C. Evoked responses to clicks and tones of varying intensity in waking adults. Electroencephalography and Clinical Neurophysiology, 1966, 28, 225-232.

Reitan, R. M. Certain differential effects of left and right cerebral lesions in human adults. Journal of Comparative Physiological Psychology, 1955, 48, 474-477.

Ritter, W., Vaughan, H. G. Averaged evoked responses in vigilance and discrimination: a reassessment. Science, 1969, 164, $326-328$.

Ritter, W., Vaughan, H. G., Jr., \& Costa, L. D. Orienting and habituation to auditory stimuli: a study of short term changes in averaged evoked responses. Electroencephalography and Clinical Neurophysiology, 1968, 25, 550-556.

Rizzolatti, G., Umilta, C., \& Berlucchi, G. Opposite superiorities of the right and left cerebral hemispheres in discriminative reaction time to physiognomical and alphabetical materials. Brain, 1971, 94, 431-442.

Robbins, K. I., \& McAdam, D. W. Interhemispheric alpha asymetry and imagery mode. Brain and Language, 1974, 1, 189-193. 
Rohrbaugh, J. W., Donchin, E., \& Eriksen, C. W. Decision making and the P300 component of the cortical evoked response. Perception and Psychophysics, 1974, 15, 368-374.

Rosenzweig, M. R. Representations of the two ears at the auditory cortex. American Journal of Physiology, 1951, 167, 147-158.

Rothman, H. H., Davis, H., \& Hay, I. S. Slow evoked cortical potentials and temporal features of stimulation. Electroencephalography and Clinical Neurophysiology, 1970, 28, 225-232.

Satterfield, J. H. Evoked cortical response enhancement and attention in man. A study of responses to auditory and shock stimuli. Electroencephalography and Clinical Neurophysiology, 1965, 19, $470-475$.

Satz, P., Richard, W., \& Daniels, A. The alteration of intellectual performance after lateralized brain-injury in man. Psychonomic Science, $1967, \underline{7}, 369-370$.

Schwent, V. L., \& Hillyard, S. A. Evoked potential correlates of selective attention with multi-channel auditory inputs. Electroencephalography and Clinical Neurophysiology, 1975, 38, 131-138.

Seamon, J. G., \& Gazzaniga, M. S. Coding strategies and cerebral laterality effects. Cognitive Psychology, 1973, $\underline{5}, 249-256$.

Shankweiler, D., \& Studdert-Kennedy, M. Identification of consonants and vowels presented to left and right ears. Quarterly Journal of Experimental Psychology, 1967, 19, 50-63.

Siegel, S. Nonparametric Statistics for the Behavioral Sciences. New York: McGraw-Hill Book Company, 1956.

Smith, D. B. A., Donchin, E., Cohen, L., \& Starx, A. Auditory averaged evoked potentials in man during selective binaural listening. Electroencephalography and Clinical Neurophysiology, $1970,28,146-152$.

Spong, P., Haider, M., \& Lindsley, D. B. Selective attentiveness and cortical evoked responses to visual and auditory stimuli. Science, 1965, 148, 395-397.

Squires, K. C., Squires, N. K., \& Hillyard, S. A. Decision-related cortical potentials during an auditory signal detection task with cued observation intervals. Journal of Experimental Psychology: Human Perception and Performance, 1975, 104, $268-279$. 
Sutton, S., Braren, M., Zubin, J., \& John, E. R. Evokedpotential correlates of stimulus uncertainty. Science, 1965, 150, 1187-1188.

Terrace, H. The effects of retinal locus and attention on the perception of words. Journal of Experimental Psychology, $1959,58,382-385$.

Terzian, H. Behavioral and EEG effects on intracarotid sodium amytal injection. Acta Neurochirurgica, 1964, 12, 230-339.

Tunturi, A. R. A study on the pathway from the medial geniculate body to the acoustic cortex in the dog. American Journal of Physiology, 1946, 147, 311-319.

Vaughan, H. C., \& Ritter, W. The sources of auditory evoked responses recorded from the numan scalp. Electroencephalography and Clinical Neurophysiology, 1970, 28, 360-367.

Wada, J. A., Clarke, R., \& Hamm, A. Cerebral hemispheric asymetry in humans. Archives of Neurology, 1975, 32, 239-246.

Wada, J. A., \& Rasmussen, T. Intracarotid injection of sodium amytal for the lateralization of cerebral speech dominance. Journal of Neurosurgery, 1960, 17, 266-282.

White, M. J. Laterality differences in perception: a review. Psychological Bulletin, 1969, 72, 387-405.

Wilson, J., Vieth, R., \& Darrow, C. W. Activation and automation in right and left hemispheres. Electroencephalography and Clinical Neurophysiology, 1957, 9 , 570-571.

Witelson, S. F., \& Pallie, W. Left hemisphere specialization for language in the newborn. Brain, 1973, 96, 641-646.

Wood, C. C. Parallel processing of auditory and phonetic information in speech discrimination. Perception and Psychophysics, 1974, 15, 501-508.

Wood, C. C. Auditory and phonetic levels of processing in speech perception: neurophysiological and information processing analyses. Journal of Experimental Psychology: Human Percepzion and Performance, 1975, 104, 3-20.

Wood, C. C., Goff, W. R., \& Day, R. S. Auditory evoked potentials during speech perception. Science, 1971, 173, 1248-1251.

Yeni-Komshian, G. H., \& Benson, D. A. Anatomical study of cerebral asymetry in the temporal lobe of humans, chimpanzees, and rhesus monkeys. Science, 1976, 192, 287-389 
Dennis A. Silva was born on December 9, 1948, in Palmer, Massachusetts. He is the son of Ermindo J. and Lucille M. Leroux Silva. He attended St. Matthew's Grade School and Cathedral High School in Springfield, Massachusetts. He received a B.A. in psychology from the University of Massachusetts in Amherst in 1970 and an M.A. in experimental psychology from the University of Hartford, Connecticut, in 1974. During his master's program, he worked as a research assistant to Bernard z. Friedlander in the Infant/Child Language Research Laboratory. While at the University of Florida Mr. Silva worked as a research assistant under the direction of William A. Yost, and as a teaching assistant to w. Keith Berg. 
I certify that I have read this study and that in my opinion it conforms to acceptable standards of scholarly presentation and is fully adequate, in scope and quality, as a dissertation for the degree of Doctor of Philosophy.

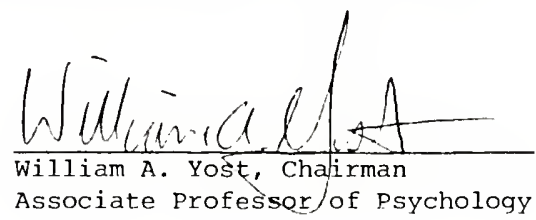

I certify that I have read this study and that in my opinion it conforms to acceptable standards of scholarly presentation and is fully adequate, in scope and quality, as a dissertation for the degree of Doctor of Philosophy.

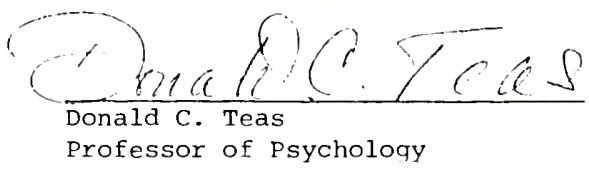

I certify that I have read this study and that in my opinion it conforms to acceptable standards of scholarly presentation and is fully adequate, in scope and quality, as a dissertation for the degree of Doctor of Philosophy.

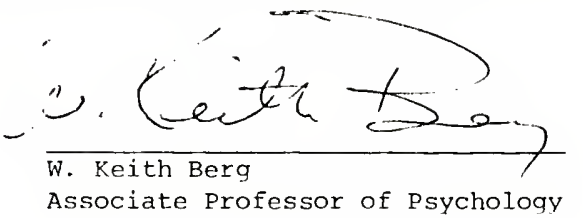

I certify that I have read this study and that in my opinion it conforms to acceptable standards of scholarly presentation and is fully adequate, in scope and quality, as a dissertation for the degree of Doctor of Philosophy.

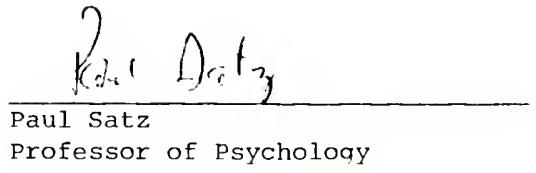


I certify that I have read this study and that in my opinion it conforms to acceptable standards of scholarly presentation and is fully adequate, in scope and quality, as a dissertation for the degree of Doctor of Philosophy.

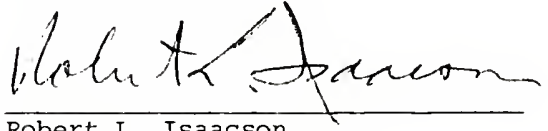

Robert L. Isaacson

Professor of Psychology

I certify that I have read this study and that in my opinion it conforms to acceptable standards of scholarly presentation and is fully adequate, in scope and quality, as a dissertation for the degree of Doctor of Philosophy.

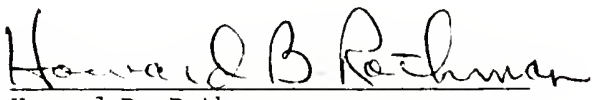
Howard B. Rothman

Associate Professor of Speech

This dissertation was submitted to the Graduate Faculty of the Department of Psychology in the College of Arts and Sciences and to the Graduate Council, and was accepted as partial fulfillment of the requirements for the degree of Doctor of Philosophy.

March, 1977

Dean, Graduate School 
UNIVERSITY OF FLORIDA

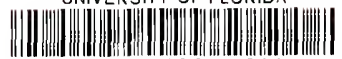

31262085529633 